\title{
The renal inflammatory network of nephronophthisis.
}

Marceau Quatredeniers ${ }^{1}$, Frank Bienaimé2,3,4, Giulia Ferri', Pierre Isnard ${ }^{3,4,5}$, Esther Porée ${ }^{1}$, Katy Billot ${ }^{1}$, Eléonore Birgy ${ }^{1}$, Salomé Ceccarelli ${ }^{1}$, Flora Legendre ${ }^{1}$, Simone Braeg ${ }^{6}$, Thao Nguyen-Khoa ${ }^{7}$, Rémi Salomon ${ }^{1,3,8}$, Marie-Claire Gubler ${ }^{1}$, E. Wolfgang Kühn ${ }^{6,9,10}$, Sophie Saunier ${ }^{1}$, Amandine Viau¹.

\section{Author Affiliations}

${ }^{1}$ Université de Paris, Imagine Institute, Laboratory of Hereditary Kidney Diseases, INSERM UMR 1163, F-75015, Paris, France.

${ }^{2}$ Department of Physiology, Necker Hospital, Assistance Publique-Hôpitaux de Paris, Paris, France.

${ }^{3}$ Université de Paris, France.

${ }^{4}$ Institut Necker-Enfants Malades, INSERM U1151, Paris, France.

${ }^{5}$ Department of Pathology, Necker Hospital, Assistance Publique-Hôpitaux de Paris, France.

${ }^{6}$ Renal Department, University Medical Center, Freiburg, Germany.

7 Laboratory of Biochemistry, Necker Hospital, Assistance Publique-Hôpitaux de Paris, Centre Université de Paris, France.

${ }^{8}$ Department of Pediatry, Necker Hospital, Assistance Publique-Hôpitaux de Paris, France.

${ }^{9}$ Faculty of Medicine, University of Freiburg, Freiburg, Germany.

10 Center for Biological Signaling Studies (BIOSS), Albert-Ludwigs-University Freiburg, Freiburg, Germany.

Corresponding author:

Amandine Viau

Inserm U1163 - Institut Imagine

Laboratory of Inherited Kidney Diseases

Team "nephronophthisis and hypodysplasia"

24 Boulevard du Montparnasse

75015 Paris

France

Phone: +3314275 4341

Email : amandine.viau@inserm.fr 


\section{ABSTRACT}

Nephronophthisis (NPH) and autosomal dominant polycystic kidney disease (ADPKD) are caused by mutations in genes encoding primary cilia proteins. In ADPKD, altered cilia signaling promotes renal inflammation through the upregulation of the macrophage chemoattractant CCL2, which subsequently fuels disease progression. While inactivation of NPHP1, the main gene involved in NPH leads to increased CCL2 expression in cultured renal epithelial cells, little is known about renal inflammation in NPH.

Here, we analyzed murine models of NPH as well as kidney tissues and urine derived renal epithelial cells (UREC) from NPH patients to dissect the renal inflammatory network involved in $\mathrm{NPH}$.

Similarly to ADPKD, NPH patients present kidney infiltration by macrophages, increased CCL2 expression by tubular cells and enhanced CCL2 urinary excretion. Yet, while tubule specific Ccl2 disruption dramatically reduced renal Ccl2 expression in a mouse model of $\mathrm{NPH}$, this did not translate into reduced macrophage infiltration nor lessened renal deterioration. In further contrast to early ADPKD, infiltrating macrophages were accompanied by neutrophils and T cells in both human and murine NPH. Through analysis of transcriptome datasets from early diseased kidneys in two distinct mouse models of NPH, we identified a set of 17 soluble inflammatory mediators, which increased independently of CCL2. Among those, 8 were also significantly upregulated in UREC from NPH patients compared to controls.

Collectively, these results unveil that mutations in ciliary proteins in NPH and ADPKD trigger divergent renal inflammatory responses. This work sheds light on the specific inflammatory network underlying NPH. 


\section{INTRODUCTION}

Renal ciliopathies $(\mathrm{RC})$ are inherited disorders affecting the kidney caused by mutations in genes encoding proteins that localize in primary cilia ${ }^{1,2}$. The primary cilium is a solitary antenna-like structure protruding from the apical surface of renal tubular cells, acting as a complex macromolecular sensor and signal transducer ${ }^{3,4}$.

$\mathrm{RC}$ share common features including tubular dilation, interstitial fibrosis and loss of tubular cell differentiation. On the other hand, the spectrum of RC encompasses genetically distinct and phenotypically heterogeneous diseases that manifest from early-childhood to lateadulthood and lead to end-stage renal disease in the majority of cases. Autosomal dominant polycystic kidney disease (ADPKD), the most common ciliopathy manifesting in adulthood, is characterized by the development of multiple renal cysts resulting in progressive enlargement of the kidneys accompanied by kidney function decline. Most ADPKD cases are caused by inactivating mutations in PKD1, which encodes polycystin 1 (PC1), a receptor-like transmembrane protein, which localized to the ciliary membrane. Contrary to ADPKD, nephronophthisis (NPH), the second most prevalent $\mathrm{RC}$, is an autosomal recessive disorder that manifests in childhood by enuresis (bedwetting) due to impaired urine concentrating ability and progressive kidney function decline. Although cysts are frequently observed in $\mathrm{NPH}$, cyst burden remains marginal compared to ADPKD, and the kidneys mostly appear small and fibrotic. NPH is a genetically heterogeneous disorder caused by mutations in more than 20 genes identified so far ${ }^{5}$. Mutations in NPHP1 are by far the most common, accounting for $40-50 \%$ of identified causative mutations in $\mathrm{NPH}^{6}$. Most of the proteins encoded by NPHP genes assemble in functional modules that control cilia morphology and gate protein entry and exit to and from the cilia ${ }^{7,8}$. Yet, how disruption of these complexes translate into pathophysiologic events to cause kidney damage is poorly understood.

Primary cilia of renal tubular cells are required for proper kidney development and maintenance ${ }^{9}$. Yet, none of the mutations reported so far in $\mathrm{RC}$ abolish ciliogenesis. While 
renal tubular cells remain ciliated in $\mathrm{RC}$, they may display either increased or decreased cilia length ${ }^{10,11}$. It is believed that the genetic defects involved in RC adversely affect cilia composition and signaling which results in modifications of tubular cell behavior that, in turn, change kidney morphology and function.

Lessons gathered from acquired chronic kidney disease models indicate that progressive renal parenchyma alteration involves multi-directional communication between tubular, immune and mesenchymal cells that prompts immune cell infiltration, fibroblasts activation and nephron loss ${ }^{12-14}$.

Concordant evidence has pinpointed an important role of renal inflammation in the progression of ADPKD. Indeed, macrophages infiltrate the kidney of ADPKD patients and mice and promote cyst growth ${ }^{15}$. Remarkably, cilia signaling seems to be directly involved in this process as cilia ablation prevents macrophage recruitment in an orthologous model of $A D P K D^{16}$. Mechanistically, cilia positively regulate the expression of the macrophage chemoattractant CCL2 in Pkd1-deficient tubular cells both in vivo and in vitro. Consistently, kidney specific disruption of Ccl2 or inhibition of the CCL2 receptor reduce cyst burden in Pkd1 mutant mice ${ }^{16,17}$.

In contrast to ADPKD, the function of immune cells in NPH has received little attention. Recent evidence however suggests that renal inflammation may be involved in the disease. First, the inactivation of TLR2, a critical receptor of the immune system, prevents renal damage in an orthologous model of a rare form of NPH caused by a mutation in Glis2/Nphp7

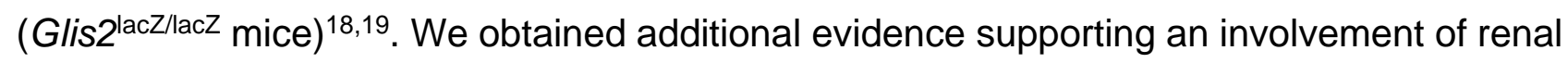
inflammation in NPH while studying the function of LKB1 in tubular cells: LKB1 is a ciliary kinase involved in the control of cell size and metabolism through the regulation of AMPK. We previously reported that LKB1 interacts with NPHP proteins including NPHP1. Strikingly, mice bearing a selective inactivation of $L k b 1$ in renal tubules ( $L k b 1^{\Delta T u b}$ mice) present with an NPH-like phenotype recapitulating the consequences of NPHP1 loss in humans. In vitro, both NPHP1 and LKB1 repress the expression of CCL2, while CCL2 upregulation and 
macrophage recruitment are observed in vivo at an early time point of the development of the disease in $L k b 1^{\Delta T u b}$ mice ${ }^{16}$. Importantly, CCL2 dependent recruitment of immune cells has been repeatedly shown to promote renal fibrosis in different acquired chronic kidney disease models ${ }^{14,20}$.

Considering the paucity of data regarding renal inflammation in $\mathrm{NPH}$, we decided to explore the interplay between immune and tubular cells in NPH though a translational approach including transgenic animals and human data. 


\section{MATERIALS AND METHODS}

\section{Human kidney tissue specimens}

Renal kidney tissue from 12 patients suffering from juvenile nephronophthisis were collected from 1973 to 1998 . Kidneys donated for transplantation $(n=5)$ but unsuitable for implantation (due to damage to the arterial patch or parenchymal sclerosis) or kidney from patient suffering renal disease other than nephronophthisis with minimal histological lesions $(n=1)$ and collected at the same time period were used as controls. Patient data are listed in Supplementary Table 1.

The human kidney tissue specimens belonging to the Imagine Biocollection are declared to the French Minister of Research under the number DC-2020-3994 and approved by the French Ethics committee for research at Assistance Publique-Hôpitaux de Paris (CERAPHP) under the IRB registration number \#00011928.

\section{Isolation of urine-derived renal epithelial cells (UREC)}

Urine samples were collected from NPHP1 patients, healthy relatives and unrelated controls with no known renal disease recruited at Necker Hospital (Paris, France) after written informed consent of the donor. Inclusion criteria for affected patients were to suffer from nephronophthisis with known genetic diagnosis. The relatives were the healthy relatives (father/mother/brother/sister) of an included patient. Healthy controls were unscathed of any chronic kidney disease. The study was approved by the French National Committee for the Protection of Persons (CPP) under the ID-RCB number 2016-A00541-50 and is kept in full accordance with the principles of the Declaration of Helsinki and Good Clinical Practice guidelines. Patient data are listed in Supplementary Table 1.

Urine-derived renal tubular epithelial cells (primary UREC) were isolated and cultured as previously described ${ }^{21}$ with some modifications. Briefly, after centrifugation and washing steps, urine-derived cells were initially cultured for 4 days at $37^{\circ} \mathrm{C}$ in primary medium containing Dulbecco's Modified Eagle Medium : Nutrient Mixture F-12 (DMEM/F-12) supplemented with $10 \%$ fetal bovine serum (16000-036, Gibco), 10\% Penicillin- 
Streptomycin (15140-122, Gibco), 10\% Amphotericin B (15290026, Gibco) and 1X REGM ${ }^{\mathrm{TM}}$ SingleQuots ${ }^{\mathrm{TM}}$ kit (CC-4127, Lonza) to enhance cell survival and adherence. At day 4, primary medium was replaced by a growth medium containing REBM ${ }^{\mathrm{TM}}$ (Basal Medium, CC3191, Lonza) supplemented with 2\% fetal bovine serum, 10\% Penicillin-Streptomycin, 10\% Amphotericin B, 1X REGM ${ }^{\mathrm{TM}}$ SingleQuots ${ }^{\mathrm{TM}} \mathrm{kit}$ and $10 \mathrm{ng} / \mathrm{mL} \mathrm{rhEGF}$ (R\&D system) and was then changed every 2 days. At $80 \%$ confluence (7-30 days), $2 \times 10^{4}$ cells were seeded for 7 24 days until confluence on 12 well plates (353043, Dutscher) for RNA analysis.

\section{Mice}

All animal experiments were conducted according to the guidelines of the National Institutes of Health Guide for the Care and Use of Laboratory Animals, as well as the German law for the welfare of animals, and were approved by regional authorities. Mice were housed in a specific pathogen-free facility, fed ad libitum and housed at constant ambient temperature in a 12-hour day/night cycle. Breeding and genotyping were done according to standard procedures.

Lkb $1^{\text {flox/flox mice (mixed genetic background) and Ccl2-RFPflox/flox }(B 6 . C g-C c l 2 t m 1.1 P a m e / J}$, stock number : 016849, C57BL/6 genetic background) were purchased from The Jackson Laboratories (STOCK Stk11tm1.1Sjm/J, stock number: 014143) and were crossed to KspCre mice (B6.Cg-Tg(Cdh16-cre)91/gr/J; C57BI/6N background) ${ }^{22}$ to generate a tubule-specific $L k b 1$ knockout (further referred to as $L k b 1^{\Delta T u b)}$ and $L k b 1 ; C c l 2$ knockout (further referred to as $\left.L k b 1^{\Delta T u b} ; C c / 2^{\Delta T u b}\right)$. Littermates lacking KspCre transgene were used as controls. Experiments were conducted on both females and males.

\section{Quantitative PCR}

Total RNAs were obtained from human UREC or mouse kidneys using RNeasy Mini Kit (Qiagen) and reverse transcribed using SuperScript II Reverse Transcriptase (Life Technologies) or High Capacity cDNA Reverse Transcription Kit (Applied Biosystems) according to the manufacturer's protocol. Quantitative PCR were performed with iTaq ${ }^{\mathrm{TM}}$ Universal SYBR® Green Supermix (Bio-Rad) on a CFX384 C1000 Touch (Bio-Rad). Hprt, 
Ppia, Rpl13, Sdha and Tbp were used as the normalization controls ${ }^{23}$. Each biological replicate was measured in technical duplicates. The primers used for qRT-PCR are listed in Supplementary Table 2.

\section{CCL2 ELISA}

For CCL2 measurement in urines from NPHP1 patients and controls, urine specimens were collected and centrifuged at $1500 \times \mathrm{g}$ for 10 minutes at $4^{\circ} \mathrm{C}$ within 4 hours of collection. Clinical and genetic data of the patients are listed in Supplementary Table 1. The supernatants were collected and stored at $-80^{\circ} \mathrm{C}$. Frozen aliquots of urine supernatants were thawed at room temperature immediately before the ELISA. The samples were used with a 2-fold dilution and were tested in duplicates. CCL2 levels in urine specimens were quantified using Human CCL2/MCP-1 Quantikine® ELISA Kit (R\&D systems, DCP00) according to the manufacturer's instructions. The plate was read using a Multiskan Sky plate reader set to subtract for wavelength and blank corrections. The optical densities were derived from 4parameter logistic regression of the standard curve. Measurement of creatinine in urine was performed in the same samples using IDMS-standardized enzymatic method on C16000 Architect analyzer (Abbott Diagnostic, Rungis, France). The results were normalized to the urinary creatinine level. Indeed, normalization by the urinary creatinine levels avoids the pitfall of concentration or dilution of urine.

\section{Morphological Analysis}

Human kidney biopsies were fixed in alcohol formalin and acetic acid and paraffin embedded, $4 \mu \mathrm{m}$ sections were stained with periodic acid-Schiff (PAS). PAS-stained full size images were recorded using a whole slide scanner Nanozoomer 560 (Hamamatsu) coupled to NDPview software (Hamamatsu).

Mouse kidneys were fixed in $4 \%$ paraformaldehyde, embedded in paraffin, and $4 \mu \mathrm{m}$ sections were stained with PAS. PAS-stained full size images were recorded using a whole slide scanner Nanozoomer 2.0 (Hamamatsu) equipped with a 20x/0.75 NA objective coupled to NDPview software (Hamamatsu). Histology score was evaluated by an independent 
observer in a blinded fashion assessing the overall lesions comprised of tubular atrophy, tubular basement thickening and cell infiltration of the whole kidney section stained with PAS.

\section{Urine and Plasma Analyses}

8-hour urine samples were obtained from mice housed in individual boxes without access to water and food. Body weight and urine excretion were measured. Urine osmolality was measured with a freezing point depression osmometer (Micro-Osmometer from Knauer or OSMOMAT 3000basic from Gonotec). Retro-orbital blood was collected from anaesthetized mice. Plasma blood urea nitrogen (BUN) was measured using urea kit (LT-UR; Labor\&Technik, Eberhard Lehmann $\mathrm{GmbH}$ ) according to the manufacturer's instructions.

\section{Immunohistochemistry}

\section{For human kidney sections}

An automated IHC stainer BOND-III (Leica Biosystems) was used. Briefly, $4 \mu \mathrm{m}$ sections of paraffin-embedded human kidney biopsies were submitted to the appropriate antigen retrieval. Then, sections were incubated with CD68 (Dako, M0814, 1:3,000), CD15 (Beckam Coulter, NIM0165, 1:200) or CD3 (Dako, A0452, 1:200) antibodies. Peroxide blocking, post primary, DAB chromogen and hematoxylin counterstaining was performed automatically using Bond polymer refine detection kit (Leica Biosystems, DS9800). The degree of interstitial cell infiltration was determined using immunostaining targeting macrophages (CD68), neutrophils (CD15) and T lymphocytes (CD3). Slides were scanned with a whole slide scanner Nanozoomer 560 (Hamamatsu). Randomly selected microscopic fields (x200) representative of the entire cortical surface were scored. The degree of cell infiltrate was quantified using ImageJ software. For CD3 and CD68, the area of DAB staining was measured after color deconvolution and intensity thresholding of the images and visualized as the ratio of DAB surface to cortical surface on each microscopic field. For CD15, the number of CD15-positive interstitial cells was quantified manually in a blinded fashion and was expressed as a ratio per $\mathrm{mm}^{2}$. 


\section{For mouse kidney sections}

Macrophage staining: $4 \mu \mathrm{m}$ sections of paraffin-embedded mouse kidneys were incubated for $20 \mathrm{~min}$ at $95^{\circ} \mathrm{C}$ in citrate buffer (Zytomed, ZUCD28) followed by avidin/biotin blocking (Vector, SP-2001). Sections were incubated with F4/80 antibody (Clone Cl:A3-1, Bio-Rad, MCA497R, 1:100) followed by biotinylated antibody (Vector, BA-4001, 1:200), HRP-labeled streptavidin (Southern Biotech, 7100-05, 1:2000) and 3-3'-diamino-benzidinetetrahydrochloride (DAB, Dako, K3468) revelation.

Neutrophil staining: $4 \mu \mathrm{m}$ sections of paraffin-embedded mouse kidneys were submitted to antigen retrieval for $20 \mathrm{~min}$ at $95^{\circ} \mathrm{C}$ in citrate buffer followed by incubation with LY6B antibody (Abcam, ab53457, 1:100). Sections were incubated with HRP-labeled secondary antibody (Vector, PI-9400, 1:200) and DAB revelation.

T cell staining: $4 \mu \mathrm{m}$ sections of paraffin-embedded mouse kidneys were incubated for 20 min at $95^{\circ} \mathrm{C}$ in Tris-EDTA pH9 buffer followed by avidin/biotin blocking. Sections were incubated with CD3 antibody (Abcam, ab16669, 1:100) followed by biotinylated antibody (GE Healthcare, RPN1004V, 1:200), HRP-labeled streptavidin (Southern Biotech, 7100-05, 1:2000) and DAB revelation.

Full size images were recorded using a whole slide scanner Nanozoomer 2.0 coupled to NDPview software. Stained area was measured with ImageJ software from full size kidney images and visualized as the percentage of stained area on kidney area.

\section{Comparative microarray data analysis}

Processing of data was carried out using R v3.6.0, RStudio and R package dplyr v1.0.1.

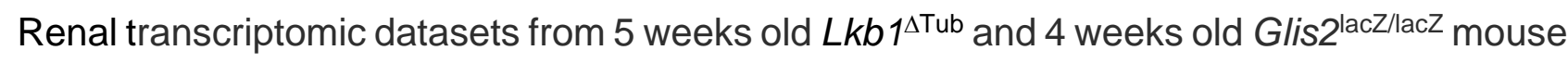
models $^{16,18}$ were compared. While transcriptomic dataset from $L k b 1^{\Delta T u b}$ mice was established by our team (GSE86011) ${ }^{16}$, we downloaded from the GEO database (https://www.ncbi.nlm.nih.gov/geo/) the expression matrix of mRNAs expressions in the kidneys of Glis2 $2^{\text {lacZ/lacZ mice under the accession number GSE6113 }}{ }^{18}$. Probe IDs in the expression matrix were matched with the corresponding gene IDs in the lookup table 
(GPL2897) to identify the expression of each mRNA. To assess the common regulated genes between the two mouse models, $L k b 1^{\Delta T u b}$ dataset was filtered out according to false discovery rate (FDR, Benjamini-Hochberg procedure) $<0.05$ to obtain a list of 1,991 differentially expressed genes (DEGs). Then, Glis2 $2^{\text {lacz/lacz }}$ dataset $(23,957$ genes) was matched with this DEGs list, and the genes whose expression varies the same way were considered the common regulated genes (1,262 genes) listed in Supplementary Table 3.

\section{GSEA, networking and visualization}

Subsequently, Gene Set Enrichment Analysis (GSEA) approach was applied to the 1,262 common regulated genes identified using GSEA software v4.0.0 (Broad Institute) set for 1,000 gene set permutations. The enrichment involved the « biological process » classification of the Gene Ontology downloaded from MSigDB v7.1 (C5-BP). Up- and downregulated pathways are listed in Supplementary Tables 4-5. Pathways with FDR $<0.05$ were considered significant. R package ggplot2 was used to present the more significant up- and down-regulated pathways. Cytoscape software v3.0 and Cytoscape applications EnrichmentMap v3.3.0 (edge cutoff threshold set to 0.6) and WordCloud v3.1.3 were used for pathway clustering and pathway network visualization ${ }^{24}$. Pathway clusters have been hand-annotated.

\section{Identification of common upregulated cytokines}

To identify common upregulated cytokines, the 823 common upregulated genes were matched with lists of genes obtained from the UniProt database (https://www.uniprot.org/) using the following keywords: «cytokine », « secreted» and « immune/inflammation ». Genes that were linked to the 3 keywords are listed in Supplementary Table 6.

\section{Statistical analysis}

Data were expressed as means. Differences between groups were evaluated using MannWhitney test when only two groups were compared or one-way ANOVA followed when significant $(P<0.05)$ by the Tukey-Kramer test when testing more comparisons. The statistical analysis was performed using GraphPad Prism V5 software. All image analysis 
bioRxiv preprint doi: https://doi.org/10.1101/2021.01.07.425719; this version posted January 8, 2021. The copyright holder for this preprint (which was not certified by peer review) is the author/funder. All rights reserved. No reuse allowed without permission.

(immunohistochemistry) and mouse phenotypic analysis were performed in a blinded fashion. 


\section{RESULTS}

Nephronophthisis is associated with macrophage recruitment and enhanced CCL2 expression.

To elucidate the contribution of immune cell recruitment in the phenotype of NPH, we first aimed to assess whether, similar to ADPKD, macrophage infiltration occurs in human NPH. Histology inspection of kidney tissues from NPH patients revealed significant infiltration by mononuclear cells (Figure 1A). Immunolabelling identified macrophages (CD68-positive cells) as an important contingent of cells infiltrating the kidneys from NPH patients as compared to control individuals (Figure 1B-C). As CCL2 has been shown to be the major chemokine responsible for macrophage recruitment in ADPKD, we analyzed primary tubular epithelial cells derived from urine (UREC) of NPHP1 patients and controls, including both age-matched controls and healthy relatives. UREC derived from patients bearing NPHP1 mutations showed increased expression of LCN2 transcript, a marker of tubular injury that positively correlates with the progression of chronic kidney disease (Supplementary Figure 1A-B). Remarkably, tubular cells derived from NPHP1 patients also markedly showed enhanced expression of CCL2 transcript (Figure 1D and Supplementary Figure 1C). Consistently, we observed that NPHP1 patients display a higher urinary excretion rate of CCL2 than controls (Figure 1E). Collectively, these data revealed that, similarly to ADPKD, $\mathrm{NPH}$ patients show increased renal tubular expression of CCL2 associated with macrophage recruitment.

\section{Tubule-specific $C c / 2$ inactivation does not prevent nephronophthisis-like phenotype.}

Tubular deletion of $\mathrm{Ccl} 2$ in ADPKD orthologous mouse model dampens renal macrophage recruitment and cyst formation ${ }^{16,17}$. The deletion of $L k b 1$ in the mouse kidney results in an NPH phenotype associated with CCL2 upregulation and macrophage recruitment ${ }^{16,25}$. To determine if the deletion of $\mathrm{Ccl} 2$ together with $L k b 1$ ameliorates the NPH-like renal disease, we crossed tubule-specific $L k b 1^{\Delta t \mathrm{tub}}$ mice with mice bearing $C c / 2$ floxed alleles and compared 
mice with inactivation of $L k b 1$ alone $\left(L k b 1^{\Delta t u b}\right)$ or $L k b 1$ and $C c l 2\left(L k b 1^{\Delta t u b}\right.$; $\left.C c l 2^{\Delta t u b}\right)$ with wildtype controls. At 10 weeks of age, quantitative RT-PCR revealed that Ccl2 inactivation in tubular cells drastically decreased the overall Ccl2 expression in Lkb1 inactivated kidneys (Figure 2A). Macroscopic inspection revealed irregular kidneys in both $L k b 1^{\Delta t u b}$ and $L k b 1^{\Delta t u b} ; C c l 2^{\Delta t u b}$ mice associated with reduced kidney size, which was even more pronounced in $L k b 1^{\Delta \mathrm{tub}} ; C c 2^{\Delta \mathrm{tub}}$ mice (Figure 2B-C). $L k b 1^{\Delta \mathrm{tub}}$ and $L k b 1^{\Delta \mathrm{tub}} ; C c l^{\Delta \mathrm{tub}}$ mice both displayed a urine concentration defect and a similar loss of kidney function (Figure 2DF). Histology revealed thickened tubular basement membranes, interstitial inflammation, fibrosis, and dilated tubules in both kidneys from $L k b 1^{\Delta \text { tub }}$ and $L k b 1^{\Delta \text { tub }} C c / 2^{\Delta t u b}$ mice and upregulation of the tubular injury marker, $L c n 2$, as well as the extracellular matrix deposition markers, Col1a1 and Tgfb1 (Figure 2G-L).

The protective effect of $\mathrm{Ccl} 2$ inactivation in ADPKD and in acquired renal disease is linked to a reduced immune cell recruitment, particularly the macrophage cell population. Unexpectedly, contrary to what was observed in Pkd1-deficient mice ${ }^{16,17}$, Ccl2 inactivation did not prevent macrophage infiltration induced by $L k b 1$ inactivation as judged by quantification of both F4/80 immunolabelling and F4/80 transcript (Adgre1) (Figure 2M-O). Collectively, these results demonstrate that, although tubular cells play a major role in the upregulation of CCL2 in Lkb1 deficient kidneys, this cytokine does not play a significant role in renal macrophage recruitment nor in the induction of NPH-like nephropathy.

\section{The nephronophthisis phenotype in mice is associated with an immune signature.}

So far, our findings revealed macrophage infiltration in NPH but, as opposed to ADPKD, this macrophage recruitment appears independent of CCL2. To approach the mechanisms underlying renal inflammation in NPH in an unbiased manner, we compared microarraybased transcriptomes from $L k b 1^{\Delta T u b}$ and Glis $2^{\text {lacZ/lacZ }}$ kidneys $^{16,18}$ to control kidneys. Notably, both mouse models recapitulated the features of human NPH: polyuria followed by 
progressive interstitial fibrosis, tubular basement membrane thickening, tubular dilations and immune cell infiltration ${ }^{26}$. We focused on transcriptome datasets obtained at an early time point of disease development (4 weeks and 5 weeks). Gene overlap analysis identified 1,262 genes that were commonly deregulated in the two mouse models (Figures $\mathbf{3 A}-\mathbf{B}$ and Supplementary Table 3). Gene set enrichment analysis (GSEA) of these genes identified a total of 72 enriched pathways (FDR<0.05). Among those pathways, 8 were downregulated, consisting mostly of metabolic processes, while 64 biological processes were upregulated (Supplementary Tables 4-5). Among the latter, the GSEA revealed a high enrichment in biological processes linked to immune response and inflammation (Figure 3C). Network analysis showed an intensive association of the common regulated genes with immune pathways (Figure 3D and Supplementary Figure 2). This unbiased analysis identified renal inflammation as a prominent and early phenomenon in the course of experimentally induced $\mathrm{NPH}$ models in the mouse.

\section{Lkb1 tubular inactivation activates multiple chemotactic pathways and drives the recruitment of distinct immune cell population independently of CCL2.}

To identify specific cytokines that might illuminate CCL2 independent immune cell recruitment in $\mathrm{NPH}$, we matched the common upregulated genes between $L k b 1^{\Delta T u b}$ and Glis2 $2^{\text {lacz/lacz }}$ kidneys with UniProt database. This analysis retrieved 17 pro-inflammatory cytokines, other than CCL2 (Figure 3E and Supplementary Table 6) that have been implicated in macrophage, neutrophil, T cell and dendritic cell chemotaxis. Quantifying these transcripts in kidneys from $L k b 1^{\Delta t \mathrm{tub}}, L k b 1^{\Delta \mathrm{tub}}$; $C c l 2^{\Delta \mathrm{tub}}$ and control mice, we observed that CCL2 disruption had no impact on the regulation of these immune mediators (Figure 4). In line with the different immune cell populations attracted by these chemokines, specific immunolabelling demonstrated enhanced neutrophils (Ly-6B positive cells) and T cells (CD3 positive cells) recruitment in both kidneys from $L k b 1^{\Delta \text { tub }}$ and $L k b 1^{\Delta t u b} ; C c l 2^{\Delta t u b}$ mice as 
compared to control mice (Figure 5). Collectively, these results uncover a CCL2 independent inflammatory network in NPH-like renal disease.

Identifying the inflammatory network associated with loss of NPHP1 function in humans.

Considering the distinct immune cell populations infiltrating the kidneys of $L k b 1^{\Delta \text { tub }}$ mice, we aimed to determine if such phenomena were also found in NPH patients. CD3 and CD15 immunostaining revealed increased $T$ cells and neutrophils recruitment to the renal parenchyma of NPH patients compared to controls (Figure 6A-B). To determine if the cytokine network that we identified as features of both $L k b 1^{\Delta \text { tub }}$ and Glis2lacz/lacz mouse models of $\mathrm{NPH}$ was relevant to human $\mathrm{NPH}$, we quantified the mRNA abundance of its components in UREC from NPHP1 patients and controls. As there are no human orthologs for CCL6, 9 and 12, we focused our analysis on the 14 other inflammatory mediators. Indeed, we found 8 transcripts upregulated in human tubular cells with NPHP1 mutations (CCL5, CXCL1, CXCL10, CXCL16, CXCL17, CX3CL1, IL1RN and LGALS9), while two were not differentially regulated (IL33 and CCL19) and 4 were not detected (CXCL9, CXCL12, CXCL14, IL34) (Figure 6C-L). Of note, no difference of these cytokines mRNA expression was observed when age-matched controls and relatives with normal kidney function were compared (Supplementary Figure 3). These data reveal that, in addition to previously described CCL2 upregulation and macrophage infiltration, NPH is associated with a specific cytokine signature and the infiltration of T cells and neutrophils. 


\section{DISCUSSION}

In sharp contrast with the abundant literature regarding the molecular mechanisms of disease progression in ADPKD, insights into the pathophysiology of NPH remain scarce. This discrepancy is in part explained by the lack of orthologous mouse models recapitulating the fibrotic disease observed in most NPH patients. Indeed, neither Nphp $1^{-/-}$nor Nphp4 ${ }^{-/-}$ mice ${ }^{27,28}$ develop renal fibrosis and only few mouse models orthologous to rare forms of the disease phenocopy the human pathology ${ }^{18,26,29}$. An additional factor limiting insights into the disease is the reduced availability of kidney tissues from NPH patients. As genetic testing has become more widely available, kidney biopsies are less and less performed in NPH.

Renal inflammation has emerged as an important mediator of renal fibrosis in acquired chronic kidney disease ${ }^{12}$. In the renal ciliopathy ADPKD, CCL2 dependent macrophage recruitment promotes disease progression ${ }^{16,17}$. Having previously shown that both NPHP1 and LKB1 repress CCL2 expression in vitro and that $L k b 1$ inactivation in mice results in an $\mathrm{NPH}$-like phenotype preceded by CCL2 upregulation and macrophage recruitment, we first sought to determine if CCL2 induction and macrophage recruitment were also hallmarks of human $\mathrm{NPH}$. In line with the data gathered from $L k b 1^{\Delta t u b}$ mice, we observed significant macrophage infiltration in kidney biopsies from NPH patients and enhanced CCL2 levels in the urine. We then assessed the role of CCL2 in $L k b 1^{\Delta t u b}$ mice renal phenotype by inactivating Ccl2 specifically in tubular cells. Unexpectedly, contrary to its effect in ADPKD models, Ccl2 invalidation had no detectable impact on the NPH phenotype of $L k b 1^{\Delta t u b}$ mice. Strikingly, CCL2 inactivation did not reduce macrophage infiltration, nor inflammatory cytokine expression in LKB1 deficient kidneys. Beyond ADPKD, CCL2 is instrumental to macrophage recruitment and kidney damage in a range of experimental renal disease including UUO, AKI, diabetic nephropathy, subtotal nephrectomy ${ }^{30}$ or in response to renal infection $^{31}$. Thus, the fact that renal inflammation and macrophage recruitment in $L k b 1^{\Delta t u b}$ mice is independent of tubular CCL2 suggests that the mechanisms driving renal 
inflammation in NPH are distinct from those in most chronic kidney disease models. To get further insight into the nature of renal inflammation in NPH, we analyzed the population of immune cells infiltrating the kidneys in human NPH and $L k b 1^{\Delta \text { tub }}$ mice. In both case, macrophage infiltration was associated with the recruitment of $\mathrm{T}$ cells and neutrophils. To assess the mediators driving early NPH pathology, we analyzed common regulated genes in the transcriptome of Glis $2^{\text {laczlacz }}$ and $L k b 1^{\Delta \text { tub }}$ kidneys, two genetically distinct mouse models of NPH. Unbiased pathway analysis of these data revealed a striking preponderance of inflammatory processes, pinpointing that early inflammation is a prominent feature of experimental NPH. Indeed, we found a large number of soluble mediators of immune activation in urinary tubular cells derived from NPH patients. We verified 8 chemokines in patient cells which are also upregulated in the kidneys from experimental NPH mouse models: CCL5, CXCL1, CXCL10, CXCL16 and CXCL17, CX3CL1, IL1RN and LGALS9. Notably, CCL5, CXCL10, CXCL16 and IL1RN have also been found to be induced in a rodent orthologous model of ADPKD, suggesting that they are part of a broader signature of early $\mathrm{RC}^{32}$. In contrast, differential expression of CXCL1, CXCL17, CX3CL1 and LGALS9 transcripts were not. Thus, these chemokines appear more specific of the early renal inflammation observed in NPH.

CXCL1 induces the recruitment of various immune cell types, especially neutrophils, through its receptor CXCR2. The CXCL1/CXCR2/neutrophil axis plays an important role in the pathology of acute kidney inflammation in different mouse models ${ }^{33-35}$. Interestingly, we observed concordant neutrophil infiltration in human NPH kidneys and mice, even at an early stage of the disease. In contrast, neutrophil recruitment does not occur in ADPKD ${ }^{16}$. As neutrophils are known to promote renal fibrosis ${ }^{36}$ it is likely that CXCL1 mediated neutrophil recruitment contributes to phenotypic changes in NPH.

Our findings add to the recently identified expression of CXCL17 in the kidney ${ }^{37}$, the last identified member of the CXC chemokine family in mammals ${ }^{38,39}$. CXCL17 attracts professional antigen presenting cells ${ }^{40}$, including macrophages, through its receptor 
CXCR8. Very little is known about the role of CXCL17 in the kidney but single-cell RNA sequencing analysis revealed that CXCL17 expression is enhanced at an early time point in murine tubulointerstitial fibrosis model ${ }^{37}$.

CX3CL1, which binds to CX3CR1, plays a major role in the recruitment of resident macrophage during kidney development ${ }^{41}$ and may increase renal macrophage abundance by prolonging their survival ${ }^{42}$. CX3CL1 has also been shown to support renal monocytes recruitment in the context of renal injury and CX3CL1/CX3CR1 inhibition has been generally shown to reduce renal fibrosis in different models of renal injury ${ }^{43-45}$.

LGALS9, a mammalian $\beta$-galactoside binding lectin, was first isolated from murine embryonic kidney ${ }^{46}$. LGALS9 is known to induce apoptosis of different immune cells, particularly cytotoxic T lymphocytes when bound to its surface receptor TIM3/HAVCR2 ${ }^{47}$. The role of LGALS9 in the kidney has not been described so far however a recent study showed that anti-TIM3 antibody ameliorates kidney injury and decreased macrophage infiltration in ischemic mouse model ${ }^{48}$.

Thus, this work identified a specific network of commonly regulated chemokines that represent plausible mediators of immune cell recruitment to NPH kidneys. We found that CCL2 isn't the 'one-all' in this process. Unexpectedly, we identified inflammation as the predominant signature in two independent models of NPH and we found that this holds true in humans. Renal inflammation plays a detrimental role in a broad range of chronic kidney disease. It is therefore tempting to speculate that the inflammatory network unveiled by our study plays a role in NPH. The fact that renal inflammation preceded the development of overt renal damage in both $L k b 1^{\Delta \text { tub }}$ and Glis $2^{\text {lacZlacZ }}$ mice supports this view. The protective effect of TLR2/MYD88 inhibition reported in Glis2 mouse model further incriminates renal inflammation as a potential driving force of NPH. However, we cannot exclude that chemokine expression and immune cell recruitment are innocent bystanders of an undefined process leading to kidney damage in NPH. In addition certain immune cells may also be protective such as T lymphocytes in the context of ADPKD ${ }^{49}$. 
This work establishes renal inflammation as a prominent feature of NPH and identifies important candidate mediators of this process that are common to NPH mice models and patients. Understanding the determinant and the function of renal inflammation in NPH will help to decipher the underlying processes responsible for renal deterioration in this orphan disease. 


\section{ACKNOWLEDGEMENTS}

We thank the technicians from the mouse histology facility (S.F.R Necker INSERM US24, Paris, France) and the department of Pathology (Necker Hospital, Paris, France) for technical assistance.

Marceau Quatredeniers and Amandine Viau were supported by by a public grant “RHU-C'ILLICO" overseen by the French National Research Agency (ANR) as part of the second “Investissements d'Avenir" program (reference: ANR-17-RHUS-0002), Frank Bienaimé was supported by EMBO ALTF 927-2013, E. Wolfgang Kuehn was supported by Deutsche Forschungsgemeinschaft KU1504/7-1 and KU1504/8-1, Sophie Saunier was supported by the Institut National de la Santé et de la Recherche Médicale (INSERM), the Ministère de l'Education Nationale de la Recherche et de la Technologie (MRT), by a State funding from the Agence Nationale de la Recherche under "Investissements d'avenir" program (ANR-10IAHU-01) and by a public grant "RHU-C'IL-LICO" overseen by the French National Research Agency (ANR) as part of the second "Investissements d'Avenir" program (reference: ANR17-RHUS-0002).

We are grateful to the patients and their families for their participation. We thank Pauline Krug, Olivia Boyer, Nathalie Biebuyck, Saoussen Krid, Marina Charbit, Romain Berthaud and Guillaume Lezmi (Pediatric Nephrology, Necker Hospital, AP-HP, Paris, France), Aurélie Hummel (Adult Nephrology, Necker Hospital, AP-HP, Paris, France), Amélie Lezmi Ryckewaert and Sophie Taque (Pediatric Hematology and Oncology, Hôpital Universitaire, Rennes, France), Odile Boespflug-Tanguy (Centre de Compétence des Leucodystrophies et Leucoencéphalopathies de Cause Rare, Pôle Femme et Enfant, Hôpital Estaing, Centre Hospitalier Universitaire de Clermont-Ferrand, Clermont-Ferrand, France), Jérôme Harambat and Brigitte Llanas (Department of Pediatrics, Bordeaux University Hospital, Bordeaux, France), Bruno Ranchin (Pediatric Nephrology, Centre Hospitalier Universitaire de Lyon, Bron, France), Elodie Merieau (Centre Hospitalier Régional Universitaire de Tours, Tours, France), Marc Fila (Centre Hospitalier Universitaire de Montpellier, Montpellier, 
France) and Tory Kalman (Semmelweis University, Budapest, Hungary) who helped the follow-up of patients. We thank Corinne Antignac and Laurence Heidet (Department of Genetics, Necker Hospital, AP-HP, Paris, France) for genetic diagnostic. We thank the Department of Clinical Research at Imagine Institute with the sponsorship team that facilitates and structures the set-up of the clinical research projects and the investigation team that prepares and ensures the follow-up of the clinical trials. 


\section{AUTHOR CONTRIBUTIONS}

A.V designed the study; M.Q, F.B, P.I, E.B, K.B, E.P, S.C, G.F, F.L, S.B, and A.V performed experiments and analyzed data; S.S, R.S and M-C.G participated to human material collection; M.Q, F.B, E.W.K, S.S and A.V drafted and revised the manuscript; all authors approved the final version of the manuscript. 
bioRxiv preprint doi: https://doi.org/10.1101/2021.01.07.425719; this version posted January 8, 2021. The copyright holder for this preprint (which was not certified by peer review) is the author/funder. All rights reserved. No reuse allowed without permission.

\section{CONFLICT OF INTEREST}

The authors declare that they have no conflict of interest. 


\section{REFERENCES}

1. Braun DA, Hildebrandt F: Ciliopathies. Cold Spring Harb. Perspect. Biol. 2017

2. Devlin LA, Sayer JA: Renal ciliopathies. Curr. Opin. Genet. Dev. [Internet] 56: 49_ 60, 2019 Available from: https://doi.org/10.1016/j.gde.2019.07.005 [cited 2019 Dec 31]

3. Reiter JF, Blacque OE, Leroux MR: The base of the cilium: Roles for transition fibres and the transition zone in ciliary formation, maintenance and compartmentalization. EMBO Rep. [Internet] 13: 608-618, 2012 Available from:

http://dx.doi.org/10.1038/embor.2012.73

4. Satir P: CILIA: Before and after. Cilia. 2017

5. Srivastava S, Molinari E, Raman S, Sayer JA: Many genes-one disease? Genetics of nephronophthisis (NPHP) and NPHP-associated disorders. Front. Pediatr. 2018

6. König J, Kranz B, König S, Schlingmann KP, Titieni A, Tönshoff B, Habbig S, Pape L, Häffner K, Hansen M, Büscher A, Bald M, Billing H, Schild R, Walden U, Hampel T, Staude H, Riedl M, Gretz N, Lablans M, Bergmann C, Hildebrandt F, Omran H, Konrad M: Phenotypic spectrum of children with nephronophthisis and related ciliopathies. Clin. J. Am. Soc. Nephrol. 12: 1974-1983, 2017

7. Sang L, Miller JJ, Corbit KC, Giles RH, Brauer MJ, Otto EA, Baye LM, Wen X, Scales SJ, Kwong M, Huntzicker EG, Sfakianos MK, Sandoval W, Bazan JF, Kulkarni P, Garcia-gonzalo FR, Seol AD, Toole JFO, Held S, Reutter HM, Lane WS, Rafiq MA, Noor A, Ansar M, Radha A, Devi R, Sheffield VC, Slusarski DC, Vincent JB, Doherty DA, Hildebrandt F, Reiter JF, Jackson PK, O'Toole JF, Held S, Reutter HM, Lane WS, Rafiq MA, Noor A, Ansar M, Devi ARR, Sheffield VC, Slusarski DC, Vincent JB, Doherty DA, Hildebrandt F, Reiter JF, Jackson PK: Mapping the NPHPJBTS-MKS protein network reveals ciliopathy disease genes and pathways. Cell 145: 513-528, 2011

8. Toriyama M, Lee C, Taylor SP, Duran I, Cohn DH, Bruel AL, Tabler JM, Drew K, 
Kelly MR, Kim S, Park TJ, Braun D, Pierquin G, Biver A, Wagner K, Malfroot A, Panigrahi I, Franco B, Al-lami HA, Yeung Y, Choi YJ, Duffourd Y, Faivre L, Rivière JB, Chen J, Liu KJ, Marcotte EM, Hildebrandt F, Thauvin-Robinet C, Krakow D, Jackson PK, Wallingford JB: The ciliopathy-associated CPLANE proteins direct basal body recruitment of intraflagellar transport machinery. Nat. Genet. 48: 648656, 2016

9. Lin F, Hiesberger T, Cordes K, Sinclair AM, Goldstein LSBB, Somlo S, Igarashi P: Kidney-specific inactivation of the KIF3A subunit of kinesin-II inhibits renal ciliogenesis and produces polycystic kidney disease. Proc. Natl. Acad. Sci. U. S. A. [Internet] 100: 5286-5291, 2003 Available from:

www.pnas.orgcgidoi10.1073pnas.0836980100 [cited 2020 Dec 14]

10. Hopp K, Ward CJ, Hommerding CJ, Nasr SH, Tuan HF, Gainullin VG, Rossetti S, Torres VE, Harris PC: Functional polycystin-1 dosage governs autosomal dominant polycystic kidney disease severity. J. Clin. Invest. 2012

11. Davis EE, Zhang Q, Liu Q, Diplas BH, Davey LM, Hartley J, Stoetzel C, Szymanska K, Ramaswami G, Logan C V., Muzny DM, Young AC, Wheeler DA, Cruz P, Morgan M, Lewis LR, Cherukuri P, Maskeri B, Hansen NF, Mullikin JC, Blakesley RW, Bouffard GG, Gyapay G, Rieger S, Tönshoff B, Kern I, Soliman NA, Neuhaus TJ, Swoboda KJ, Kayserili H, Gallagher TE, Lewis RA, Bergmann C, Otto EA, Saunier S, Scambler PJ, Beales PL, Gleeson JG, Maher ER, Attié-Bitach T, Dollfus H, Johnson CA, Green ED, Gibbs RA, Hildebrandt F, Pierce EA, Katsanis N: TTC21B contributes both causal and modifying alleles across the ciliopathy spectrum. Nat. Genet. 2011

12. Andrade-Oliveira V, Foresto-Neto O, Watanabe IKM, Zatz R, Câmara NOS: Inflammation in renal diseases: New and old players. Front. Pharmacol. 2019

13. Bienaimé F, Muorah M, Yammine L, Burtin M, Nguyen C, Baron W, Garbay S, Viau A, Broueilh M, Blanc T, Peters D, Poli V, Anglicheau D, Friedlander G, Pontoglio M, 
Gallazzini M, Terzi F: Stat3 Controls Tubulointerstitial Communication during CKD. J. Am. Soc. Nephrol. 27: 2016

14. Kitagawa K, Wada T, Furuichi K, Hashimoto H, Ishiwata Y, Asano M, Takeya M, Kuziel WA, Matsushima K, Mukaida N, Yokoyama H: Blockade of CCR2 ameliorates progressive fibrosis in kidney. Am J Pathol 165: 237-246, 2004

15. Karihaloo A, Koraishy F, Huen SC, Lee Y, Merrick D, Caplan MJ, Somlo S, Cantley LG: Macrophages Promote Cyst Growth in Polycystic Kidney Disease. J. Am. Soc. Nephrol. 22: 1809-1814, 2011

16. Viau A, Bienaimé F, Lukas K, Todkar APAP, Knoll M, Yakulov TATA, Hofherr A, Kretz O, Helmstädter M, Reichardt W, Braeg S, Aschman T, Merkle A, Pfeifer D, Dumit VIVI, Gubler MM-C, Nitschke R, Huber TB, Terzi F, Dengjel J, Grahammer F, Köttgen M, Busch H, Boerries M, Walz G, Triantafyllopoulou A, Kuehn EWW: Cilialocalized LKB 1 regulates chemokine signaling, macrophage recruitment, and tissue homeostasis in the kidney . EMBO J. 37: 1-21, 2018

17. Cassini MF, Kakade VR, Kurtz E, Sulkowski P, Glazer P, Torres R, Somlo S,

Cantley LG: Mcp1 Promotes Macrophage-Dependent Cyst Expansion in Autosomal Dominant Polycystic Kidney Disease. 2018 Available from:

https://doi.org/10.1681/ASN.2018050518 [cited 2020 Jan 9]

18. Attanasio M, Uhlenhaut NH, Sousa VH, O'Toole JF, Otto E, Anlag K, Klugmann C, Treier AC, Helou J, Sayer JA, Seelow D, Nürnberg G, Becker C, Chudley AE, Nürnberg P, Hildebrandt F, Treier M: Loss of GLIS2 causes nephronophthisis in humans and mice by increased apoptosis and fibrosis. Nat. Genet. 39: 1018-1024, 2007

19. Jin H, Zhang Y, Liu D, Wang SS, Ding Q, Rastogi P, Purvis M, Wang A, Elhadi S, Ren C, Cao C, Chai Y, Igarashi P, Jetten AM, Lu D, Attanasio M: Innate Immune Signaling Contributes to Tubular Cell Senescence in the Glis2 Knockout Mouse Model of Nephronophthisis. Am. J. Pathol. [Internet] 190: 176-189, 2019 Available 
from:

http://www.ncbi.nlm.nih.gov/pubmed/31676329\%0Ahttps://linkinghub.elsevier.com/re trieve/pii/S0002944019307618

20. Braga TT, Correa-Costa M, Silva RC, Cruz MC, Hiyane MI, da Silva JS, Perez KR, Cuccovia IM, Camara NOS: CCR2 contributes to the recruitment of monocytes and leads to kidney inflammation and fibrosis development. Inflammopharmacology 1-9, 2017

21. Ajzenberg H, Slaats GG, Stokman MF, Arts HH, Logister I, Kroes HY, Renkema KY, van Haelst MM, Terhal PA, van Rooij IA, Keijzer-Veen MG, Knoers N V., Lilien MR, Jewett MA, Giles $\mathrm{RH}$ : Non-invasive sources of cells with primary cilia from pediatric and adult patients. Cilia [Internet] 4: 2015 Available from: /pmc/articles/PMC4450497/?report=abstract [cited 2020 Jun 30]

22. Shao X, Somlo S, Igarashi P: Epithelial-specific Cre/lox recombination in the developing kidney and genitourinary tract. J. Am. Soc. Nephrol. 13: 1837-1846, 2002

23. Vandesompele J, De Preter K, Pattyn F, Poppe B, Van Roy N, De Paepe A, Speleman F: Accurate normalization of real-time quantitative RT-PCR data by geometric averaging of multiple internal control genes. Genome Biol. 3: 1-12, 2002

24. Reimand J, Isserlin R, Voisin V, Kucera M, Tannus-Lopes C, Rostamianfar A, Wadi L, Meyer M, Wong J, Xu C, Merico D, Bader GD: Pathway enrichment analysis and visualization of omics data using g:Profiler, GSEA, Cytoscape and EnrichmentMap. Nat. Protoc. 2019

25. Han SH, Malaga-Dleguez L, Chinga F, Kang HM, Tao J, Reidy K, Susztak K: Deletion of Lkb1 in renal tubular epithelial cells leads to CKD by altering metabolism. J. Am. Soc. Nephrol. 2016

26. Kim Y-S, Kang HS, Herbert R, Beak JY, Collins JB, Grissom SF, Jetten AM: Kruppel-Like Zinc Finger Protein Glis2 Is Essential for the Maintenance of Normal 
Renal Functions. Mol. Cell. Biol. 28: 2358-2367, 2008

27. Jiang ST, Chiou YY, Wang E, Lin HK, Lee SP, Lu HY, Wang CKL, Tang MJ, Li H: Targeted disruption of Nphp1 causes male infertility due to defects in the later steps of sperm morphogenesis in mice. Hum. Mol. Genet. 17: 3368-3379, 2008

28. Won J, de Evsikova CM, Smith RS, Hicks WL, Edwards MM, Longo-Guess C, Li T, Naggert JK, Nishina PM: NPHP4 is necessary for normal photoreceptor ribbon synapse maintenance and outer segment formation, and for sperm development. Hum. Mol. Genet. 20: 482-496, 2011

29. Airik R, Slaats GG, Guo Z, Weiss AC, Khan N, Ghosh A, Hurd TW, Bekker-Jensen S, Schrøder JM, Elledge SJ, Andersen JS, Kispert A, Castelli M, Boletta A, Giles $\mathrm{RH}$, Hildebrandt F: Renal-retinal ciliopathy gene Sdccag8 regulates DNA damage response signaling. J. Am. Soc. Nephrol. 25: 2573-2583, 2014

30. Akli Ayoub M, Zhang Y, Kelly RS, See HB, M Johnstone EK, McCall EA, Williams JH, Kelly DJ, G Pfleger KD: Functional Interaction between Angiotensin II Receptor Type 1 and Chemokine (C-C Motif) Receptor 2 with Implications for Chronic Kidney Disease. 2015 Available from: www.nhmrc.gov.au [cited 2020 Dec 21]

31. Berry MR, Mathews RJ, Ferdinand JR, Kuper C, Jing C, Loudon KW, Wlodek E, Dennison TW, Neuhofer W, Clatworthy MR: Renal Sodium Gradient Orchestrates a Dynamic Antibacterial Defense Zone In Brief Sodium gradient guides the migration of innate immune cells in the kidney during infections. Article Renal Sodium Gradient Orchestrates a Dynamic Antibacterial Defense Zone. Cell [Internet] 170: 860-874, 2017 Available from:

http://dx.doi.org/10.1016/j.cell.2017.07.022http://dx.doi.org/10.1016/j.cell.2017.07.02 2 [cited 2020 Dec 21]

32. Zhang C, Balbo B, Ma M, Zhao J, Tian X, Kluger Y, Somlo S: Cyclin-Dependent Kinase 1 Activity Is a Driver of Cyst Growth in Polycystic Kidney Disease. J. Am. Soc. Nephrol. 2020 
33. Liu P, Li X, Lv W, Xu Z: Inhibition of CXCL1-CXCR2 axis ameliorates cisplatininduced acute kidney injury by mediating inflammatory response. Biomed. Pharmacother. 2020

34. Ranganathan P, Jayakumar C, Manicassamy S, Ramesh G: CXCR2 knockout mice are protected against DSS-colitis-induced acute kidney injury and inflammation. Am. J. Physiol. - Ren. Physiol. 2013

35. Brown HJ, Lock HR, Wolfs TGAM, Buurman WA, Sacks SH, Robson MG: Toll-like receptor 4 ligation on intrinsic renal cells contributes to the induction of antibodymediated glomerulonephritis via CXCL1 and CXCL2. J. Am. Soc. Nephrol. 2007

36. Wang H, Gao M, Li J, Sun J, Wu R, Han D, Tan J, Wang J, Wang B, Zhang L, Dong Y: MMP-9-positive neutrophils are essential for establishing profibrotic microenvironment in the obstructed kidney of UUO mice. Acta Physiol. 227: 1-13, 2019

37. Conway B, O'Sullivan E, Cairns C, O'Sullivan J, Simpson D, Salzano A, Connor K, Ding P, Humphries D, Stewart K, Teenan O, Henderson N, Benezech C, Ramachandran P, Ferenbach D, Hughes J, Chandra T, Denby L: Kidney single-cell atlas reveals myeloid heterogeneity in progression and regression of kidney disease. J. Am. Soc. Nephrol. 2020

38. Pisabarro MT, Leung B, Kwong M, Corpuz R, Frantz GD, Chiang N, Vandlen R, Diehl LJ, Skelton N, Kim HS, Eaton D, Schmidt KN: Cutting Edge: Novel Human Dendritic Cell- and Monocyte-Attracting Chemokine-Like Protein Identified by Fold Recognition Methods. J. Immunol. 2006

39. Weinstein EJ, Head R, Griggs DW, Sun D, Evans RJ, Swearingen ML, Westlin MM, Mazzarella R: VCC-1, a novel chemokine, promotes tumor growth. Biochem. Biophys. Res. Commun. 2006

40. Xiao S, Xie W, Zhou L: Mucosal chemokine CXCL17: What is known and not known. Scand. J. Immunol. 2020 
41. Liu F, Dai S, Feng D, Qin Z, Peng X, Sakamuri SSVP, Ren M, Huang L, Cheng M, Mohammad KE, Qu P, Chen Y, Zhao C, Zhu F, Liang S, Aktas BH, Yang X, Wang H, Katakam PVG, Busija DW, Fischer T, Datta PK, Rappaport J, Gao B, Qin X: Distinct fate, dynamics and niches of renal macrophages of bone marrow or embryonic origins. Nat. Commun. 2020

42. Lionakis MS, Swamydas M, Fischer BG, Plantinga TS, Johnson MD, Jaeger M, Green NM, Masedunskas A, Weigert R, Mikelis C, Wan W, Lee CCR, Lim JK, Rivollier A, Yang JC, Laird GM, Wheeler RT, Alexander BD, Perfect JR, Gao JL, Kullberg BJ, Netea MG, Murphy PM: CX3CR1-dependent renal macrophage survival promotes Candida control and host survival. J. Clin. Invest. 2013

43. Furuichi K, Gao JL, Murphy PM: Chemokine receptor CX3CR1 regulates renal interstitial fibrosis after ischemia-reperfusion injury. Am. J. Pathol. 2006

44. Song $\mathrm{KH}$, Park J, Park JH, Natarajan $\mathrm{R}$, Ha H: Fractalkine and its receptor mediate extracellular matrix accumulation in diabetic nephropathy in mice. Diabetologia 2013

45. Peng X, Zhang J, Xiao Z, Dong Y, Du J: CX3CL1-CX3CR1 Interaction Increases the Population of Ly6C - CX3CR1 hi Macrophages Contributing to Unilateral Ureteral Obstruction-Induced Fibrosis . J. Immunol. 2015

46. Wada J, Kanwar YS: Identification and characterization of galectin-9, a novel $\beta$ galactoside-binding mammalian lectin. J. Biol. Chem. 1997

47. Fujita K, Iwama H, Oura K, Tadokoro T, Samukawa E, Sakamoto T, Nomura T, Tani J, Yoneyama H, Morishita A, Himoto T, Hirashima M, Masaki T: Cancer therapy due to apoptosis: Galectin-9. Int. J. Mol. Sci. 2017

48. Guo Y, Zhang J, Lai X, Chen M, Guo Y: Tim-3 exacerbates kidney ischaemia/reperfusion injury through the TLR-4/NF-KB signalling pathway and an NLR-C4 inflammasome activation. Clin. Exp. Immunol. 2018

49. Kleczko EK, Marsh KH, Tyler LC, Furgeson SB, Bullock BL, Altmann CJ, Miyazaki M, Gitomer BY, Harris PC, Weiser-Evans MCM, Chonchol MB, Clambey ET, 
bioRxiv preprint doi: https://doi.org/10.1101/2021.01.07.425719; this version posted January 8, 2021. The copyright holder for this preprint (which was not certified by peer review) is the author/funder. All rights reserved. No reuse allowed without permission.

Nemenoff RA, Hopp K: CD8+ T cells modulate autosomal dominant polycystic kidney disease progression. Kidney Int. 2018 


\section{FIGURE LEGENDS}

\section{Figure 1. Human nephronophthisis is associated with renal inflammation,} macrophage recruitment and CCL2 upregulation.

(A) Representative images of Periodic Acid-Schiff (PAS) stained kidney biopsies from

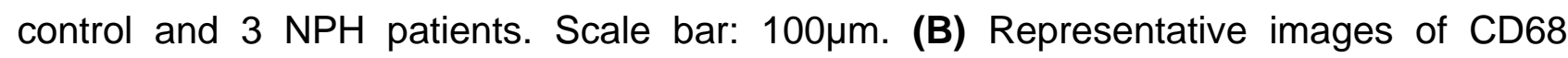
(macrophages) immunostaining in kidney biopsies from control and 3 NPH patients. Scale bar: $100 \mu \mathrm{m}$. (C) Quantification of CD68-positive staining area in kidney sections from control and NPH patients. (D) CCL2 mRNA expression in primary UREC derived from urine from 10 controls (Controls) and 9 NPHP1 patients (Patients). (E) Urinary CCL2 secretion in Controls and NPHP1 patients. (C-E) Each dot represents one individual. Bars indicate mean. Mann-Whitney t test, ${ }^{* * *} \mathrm{P}<0.001$. AU: arbitrary unit.

Figure 2. Tubule specific $\mathrm{Ccl} 2$ inactivation does not prevent renal lesion development nor macrophage recruitment in response to $L k b 1$ disruption. (A) Ccl2 mRNA expression in kidneys from control, $L k b 1^{\Delta T u b}$ and $L k b 1^{\Delta T u b} ; C c l 2^{\Delta T u b}$ mice at 10 weeks. (B) Representative kidneys from 10 weeks old control, $L k b 1^{\Delta T u b}$ and $L k b 1^{\Delta T u b} ; C c l 2^{\Delta T u b}$ mice. Scale bar: $5 \mathrm{~mm}$. (C) Kidney weight to body weight ratio (KW/BW) at 10 weeks. (D-E) Urinary flow rate (D) and urine osmolality (E) at 10 weeks. (F) Plasma blood urea nitrogen (BUN) at 10 weeks. (G) Representative PAS stained kidney sections from 10 weeks old control, $L k b 1^{\Delta T u b}$ and $L k b 1^{\Delta T u b} ; C c l 2^{\Delta T u b}$ mice. Scale bars: $5 \mathrm{~mm}$ (left panel), $100 \mu \mathrm{m}$ (middle, right panel). (H) Histology score based on PAS-stained sections from control, $L k b 1^{\Delta T u b}$ and

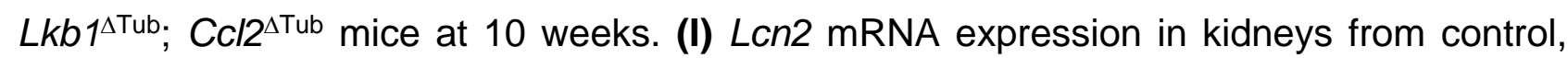
$L k b 1^{\Delta T u b}$ and $L k b 1^{\Delta T u b} ; C c l 2^{\Delta T u b}$ mice at 10 weeks. (J) Representative sirius red stained kidney sections from 10 weeks old control, $L k b 1^{\Delta T u b}$ and $L k b 1^{\Delta T u b} ; C c l 2^{\Delta T u b}$ mice. Scale bars: 5mm (left panel), 100 $\mathrm{mm}$ (right panel). (K, L) Col1a1 and Tgfb1 mRNA expression in kidneys from control, $L k b 1^{\Delta T u b}$ and $L k b 1^{\Delta T u b} ; C c / 2^{\Delta T u b}$ mice at 10 weeks. (M) Representative images of $F 4 / 80$ (macrophages) immunostaining of kidney sections from control, $L k b 1^{\Delta T u b}$ and 
Lkb1 ${ }^{\Delta \text { Tub; }}$ Ccl2 $2^{\Delta T u b}$ mice at 10 weeks. Scale bar: $100 \mu m$. (N) Quantification of F4/80 positive staining area in whole sections from 10 weeks old control, $L k b 1^{\Delta T u b}$ and $L k b 1^{\Delta T u b} ; C c l 2^{\Delta T u b}$ mice. (0) Adgre1 mRNA expression in kidneys from control, $L k b 1^{\Delta \mathrm{Tub}}$ and $L k b 1^{\Delta \mathrm{Tub}} ; C c / 2^{\Delta T u b}$ mice at 10 weeks. (A, C-F, H-I, K-L, N-O) Each dot represents one individual mouse. Bars indicate mean. One-way ANOVA followed by Tukey-Kramer test, ns: not significant, ${ }^{*} \mathrm{P}<0.05,{ }^{* *} \mathrm{P}<0.01,{ }^{* \star *} \mathrm{P}<0.001$. AU: arbitrary unit.

Figure 3. Comparative renal transcriptome analysis in Glis2 mutant mice and kidneyspecific $L \boldsymbol{k b 1}$ deficient mice ( $\left.L \boldsymbol{k b} \mathbf{1}^{\Delta \mathrm{Tub}}\right)$. (A) Venn diagram showing intersection between

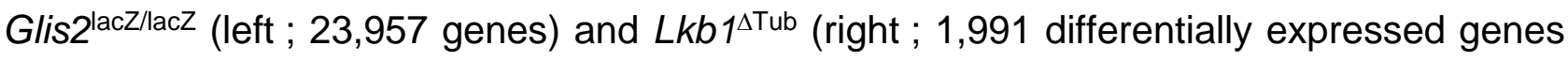
(DEGs) according to FDR < 0.05) datasets. Red numbers: upregulated; blue numbers: downregulated. (B) Jointly up- and down-regulated genes in Lkb1 $1^{\Delta T u b}$ mice (Lkb1 dataset)

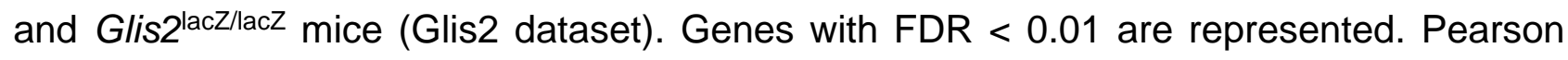
correlation $R^{2}=0.56, P<0.0001$. (C) Gene set enrichment analysis (GSEA) on the 1,262 common regulated genes revealed 72 pathways overrepresented (FDR < 0.05); the 20 most significantly upregulated are presented. See also Supplementary Tables 4-5. (D) Summarized subnetwork representation of significantly enriched Biological Processes GO terms (MSigDB v7.1, C5-BP) linked to immune/inflammatory pathways derived from the GSEA of the 1,262 common regulated genes between Glis2lacZ/lacZ and $L k b 1^{\Delta T u b}$ kidney transcriptomes. Nodes are connected according to a similarity score $>0.6$, and pathway clusters are hand-annotated according to the most representative GO-BP terms. (E) Heatmap of the 17 pro-inflammatory cytokines identified. Heat map shows Log2 fold change expression of these cytokines in the $L k b 1^{\Delta T u b}$ kidney dataset comparing control $(n=5)$ and $L k b 1^{\Delta T u b}(n=5)$ at 5 weeks of age. Each row indicate individual gene and each column shows individual mouse. (C-E) Schemes were generated using $R$ v3.6.0, $R$ studio and the package pheatmap v1.0.12. 
Figure 4. Pro-inflammatory cytokines are upregulated in nephronophthisis mouse model. (A-Q) Quantification of $C c / 5$ (A), Ccl6 (B), Ccl9 (C), Ccl12 (D), Ccl19 (E), Cx3cl1 (F), Cxcl1 (G), Cxcl9 (H), Cxcl10 (I), Cxcl12 (J), Cxcl14 (K), Cxcl16 (L), Cxcl17 (M), Il1rn (N), II33 (O), II34 (P) and Lgals9 (Q) mRNA abundance in kidneys from 10 weeks old control, $L k b 1^{\Delta T u b}$ and $L k b 1^{\Delta T u b} ; C c 2^{\Delta T u b}$ mice. Each dot represents one individual mouse. Bars indicate mean. One-way ANOVA followed by Tukey-Kramer test, ns: not significant, ${ }^{*} \mathrm{P}<0.05,{ }^{* *} \mathrm{P}<0.01,{ }^{* *} \mathrm{P}<0.001$. AU: arbitrary unit.

Figure 5. Inflammatory infiltrate is a common feature in nephronophthisis mouse model. (A) Representative images of Ly6B (neutrophils) immunostaining of kidney sections from control, $L k b 1^{\Delta T u b}$ and $L k b 1^{\Delta T u b} ; C c / 2^{\Delta T u b}$ mice at 10 weeks. Scale bar: $100 \mu m$.

Quantification of Ly6B positive staining area in whole sections from 10 weeks old control, $L k b 1^{\Delta T u b}$ and $L k b 1^{\Delta T u b} ; C c l 2^{\Delta T u b}$ mice. (C) Representative images of CD3 (T lymphocytes) immunostaining of kidney sections from control, $L k b 1^{\Delta T u b}$ and $L k b 1^{\Delta T u b} ; C c l 2^{\Delta T u b}$ mice at 10 weeks. Scale bar: 100 $\mu$ m. (D) Quantification of CD3 positive staining area in whole sections from 10 weeks old control, $L k b 1^{\Delta T u b}$ and $L k b 1^{\Delta T u b} ; C c / 2^{\Delta T u b}$ mice. (E) Cd3 mRNA expression in kidneys from control, $L k b 1^{\Delta T u b}$ and $L k b 1^{\Delta T u b} ; C c l 2^{\Delta T u b}$ mice at 10 weeks. (B, D-E) Each dot represents one individual mouse. Bars indicate mean. One-way ANOVA followed by Tukey-Kramer test, ns: not significant, ${ }^{*} \mathrm{P}<0.05,{ }^{* * *} \mathrm{P}<0.001$. AU: arbitrary unit.

Figure 6. Human nephronophthisis is associated with T lymphocytes and neutrophils recruitment linked to upregulated pro-inflammatory cytokines. (A) Representative images and quantification of CD15 (neutrophils) immunostaining of kidney biopsies from control and NPH patients. Scale bar: $100 \mu \mathrm{m}$. Asterisk: unspecific tubular staining, black arrow: intravascular neutrophils in glomerulus, red arrow, interstitial neutrophils. Representative images and quantification of CD3 (T lymphocytes) immunostaining of kidney biopsies from control and NPH patients. Scale bar: 100um. (C-L) CCL5 (C), CCL19 (D), CX3CL1 (E), CXCL1 (F), CXCL10 (G), CXCL16 (H), CXCL17 (I), IL1RN (J), IL33 (K), 
LGALS9 (L) mRNA expression in primary UREC derived from urine from controls (Controls) and NPHP1 patients (Patients). (A-L) Each dot represents one individual. Bars indicate mean. Mann-Whitney t test, ns: not significant, ${ }^{*} P<0.05,{ }^{* *} P<0.01,{ }^{* *} P<0.001$. AU: arbitrary unit. 
bioRxiv preprint doi: https://doi.org/10.1101/2021.01.07.425719; this version posted January 8, 2021. The copyright holder for this preprint (which was not certified by peer review) is the author/ffFidgurêl lights reserved. No reuse allowed without permission.

A Control • Patients •

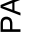

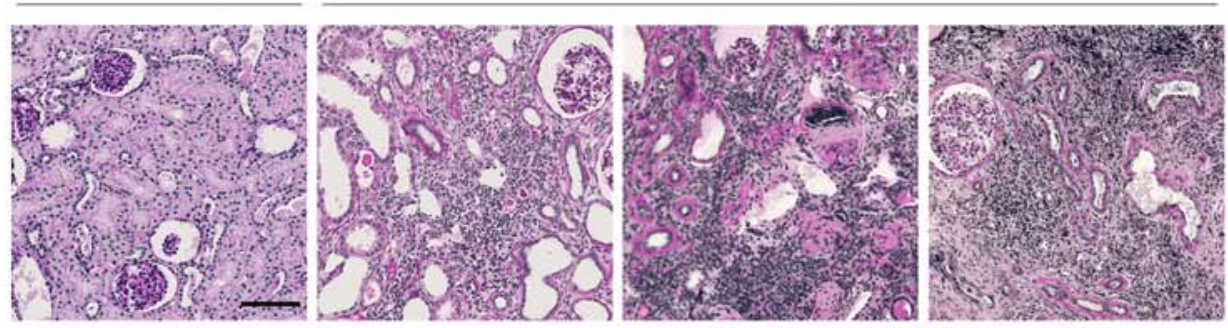

B Control • Patients -

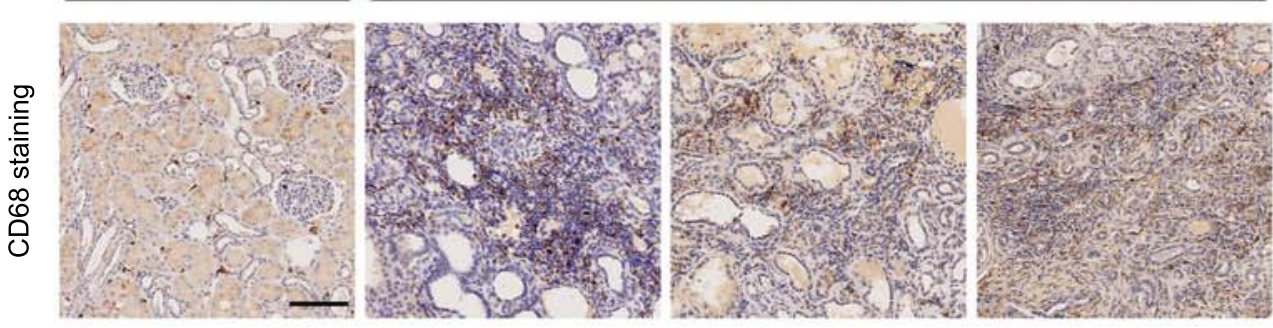

C

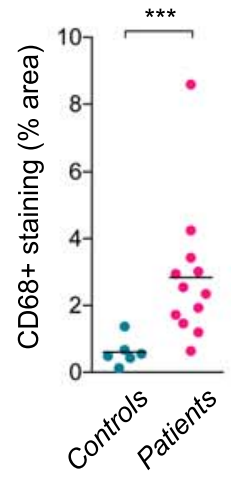

D

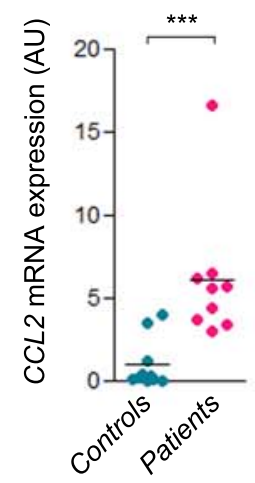

E

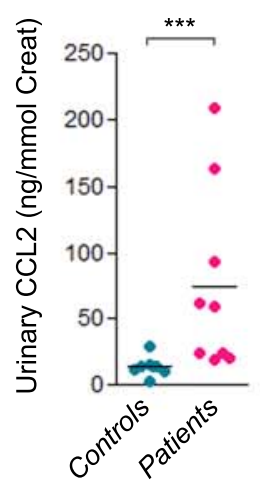


bioRxiv preprint doi: https://doi.org/10.1101/2021.01.07.425719; this version posted January 8, 2021. The copyright holder for this preprint (which was not certified by peer review) is the author/fuhdgun ights reserved. No reuse allowed without permission.

A

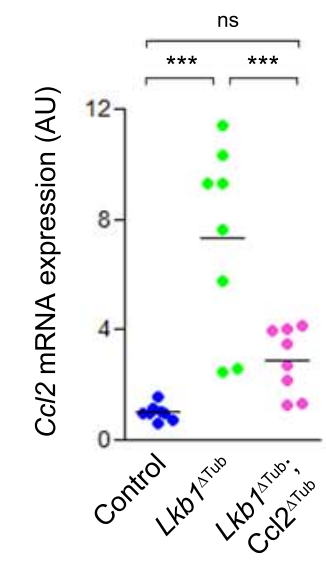

B

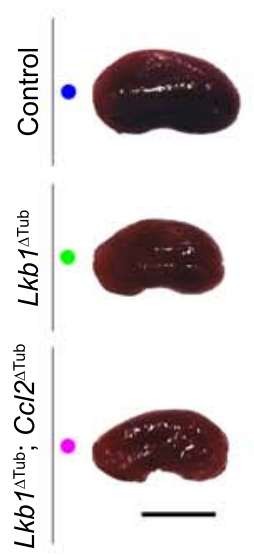

C

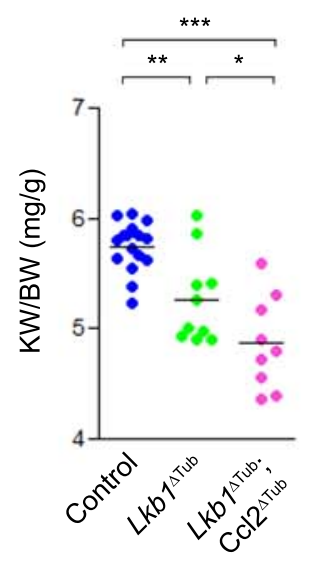

D

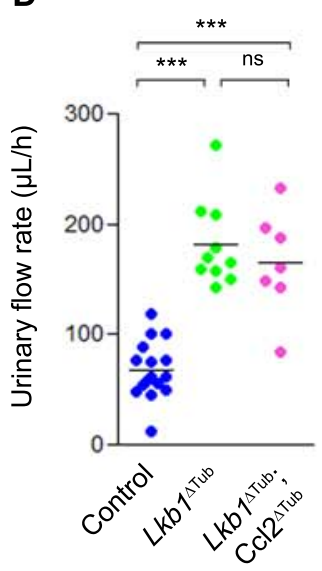

E

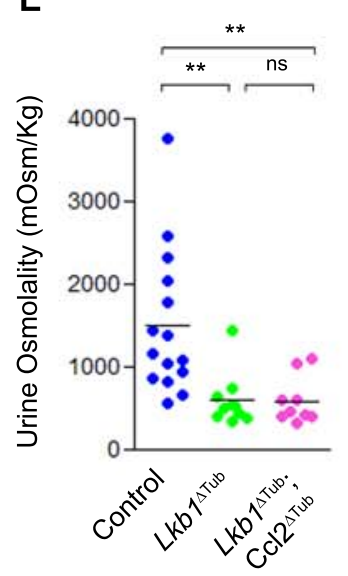

\section{F}

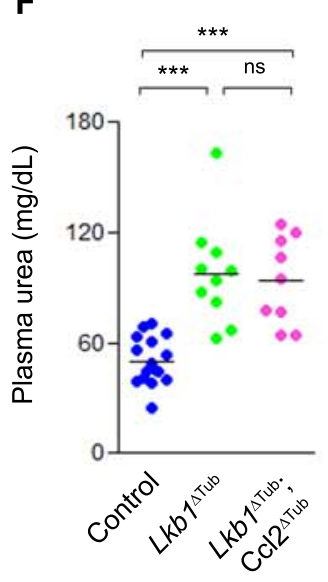

G
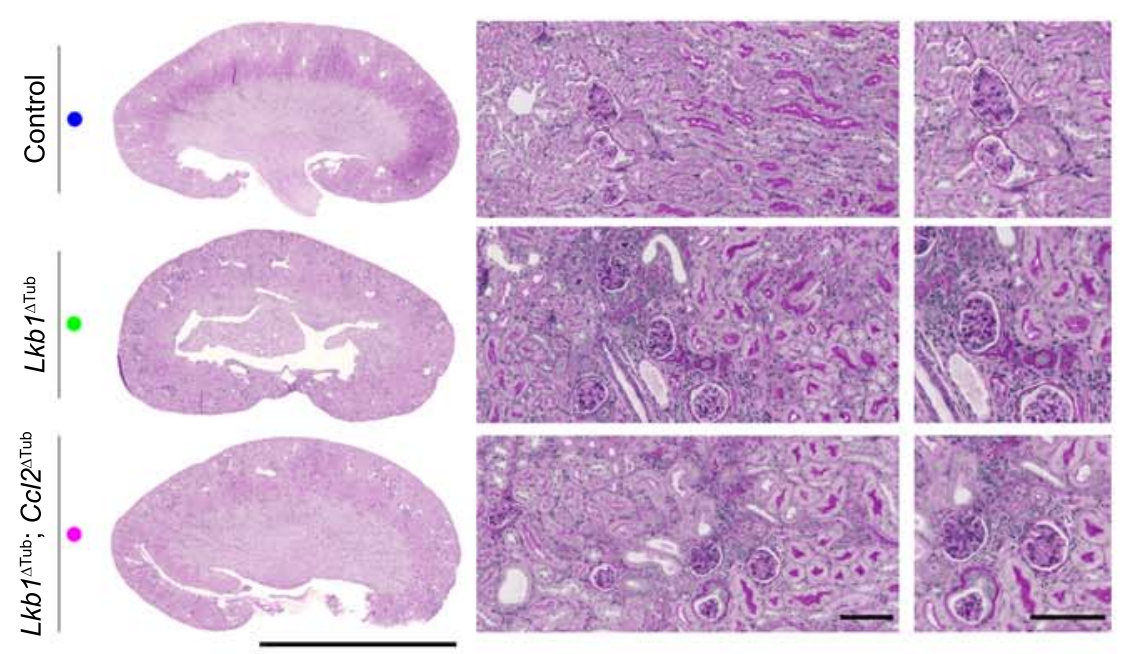

J
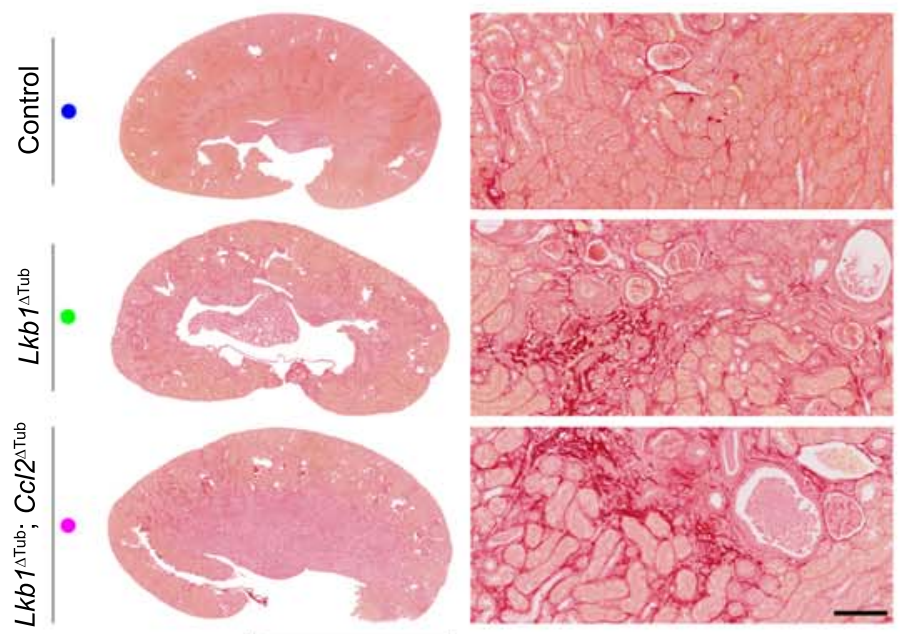

M

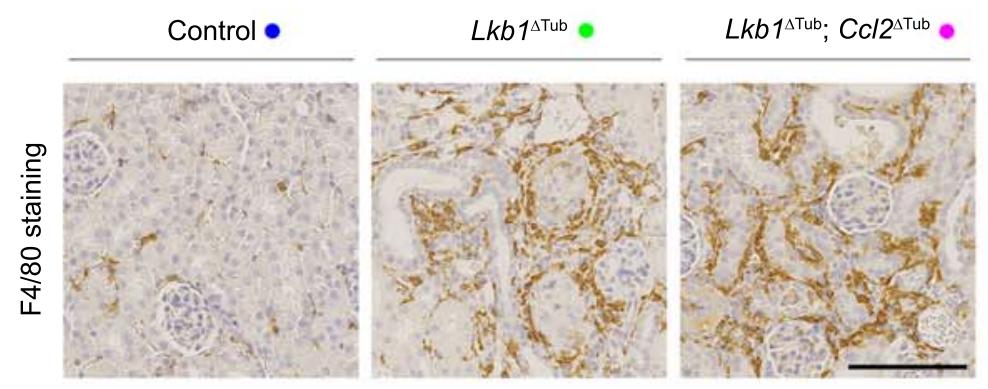

H

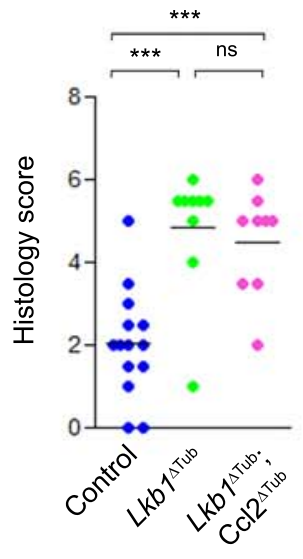

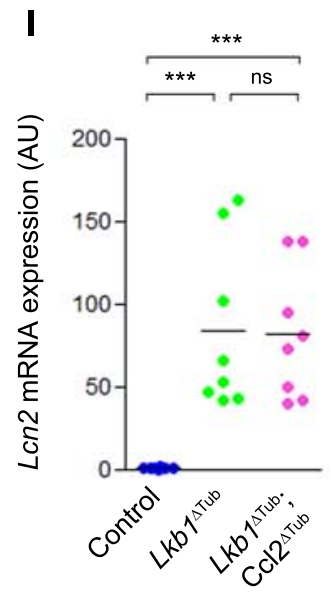
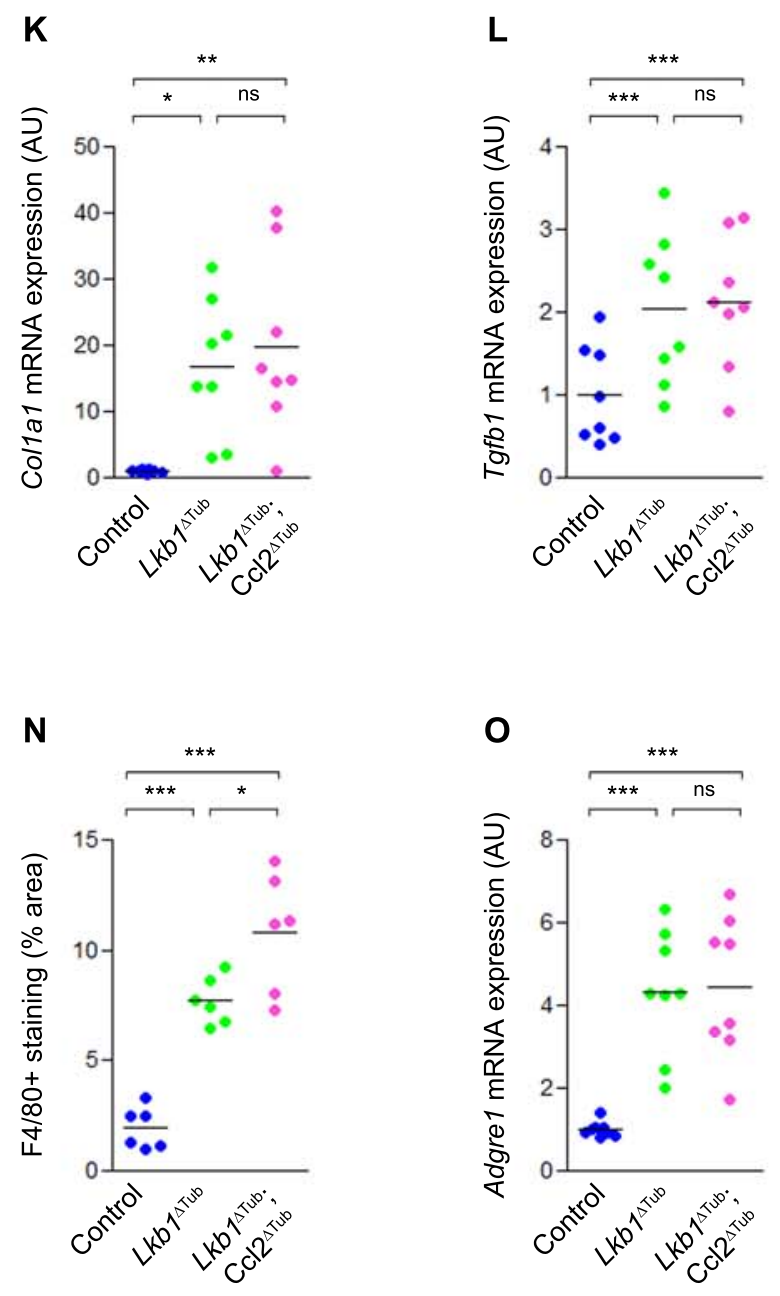
bioRxiv preprint doi: https://doi.org/10.1101/2021.01.07.425719; this version posted January 8, 2021. The copyright holder for this preprint

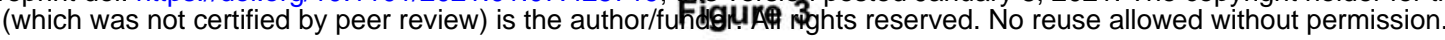

A

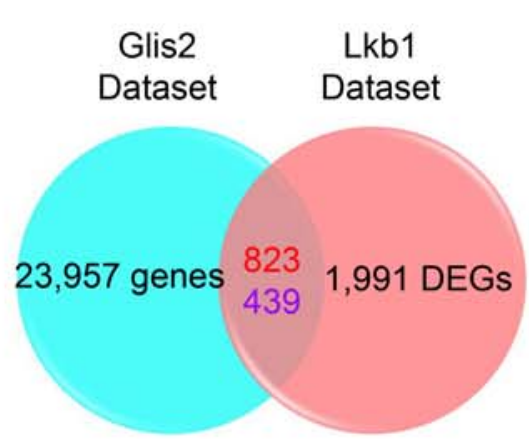

D

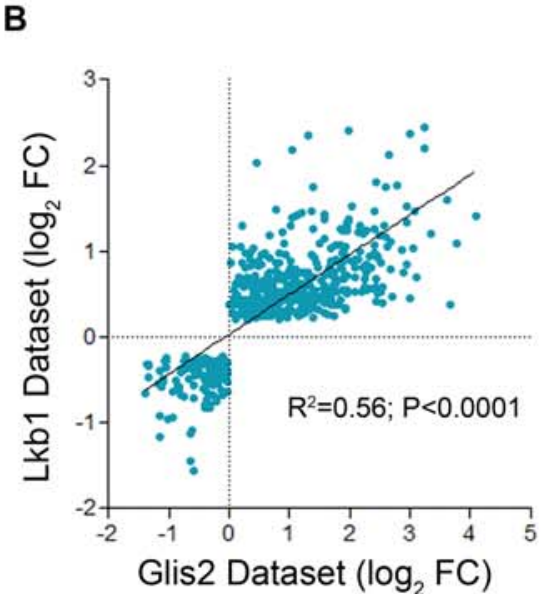

C Lymphocyte Mediated Immunity
Innate Immune Response
Regulation of Immune Effector Process
Cell Killing
Defense Response to Other Organisms
Inflammatory Response
Regulation of Immune Response
Cell Chemotaxis
Defense Response
Skeletal System Development
Extracellular Structure Organization
Leukocyte Migration
Response to Biotic Stimulus
Leukocyte Mediated Immunity
Adaptive Immune Response Based
Leukocyte Chemotaxis
Collagen Fibril Organization
Regulation of Defense Response
Acute Inflammatory Response

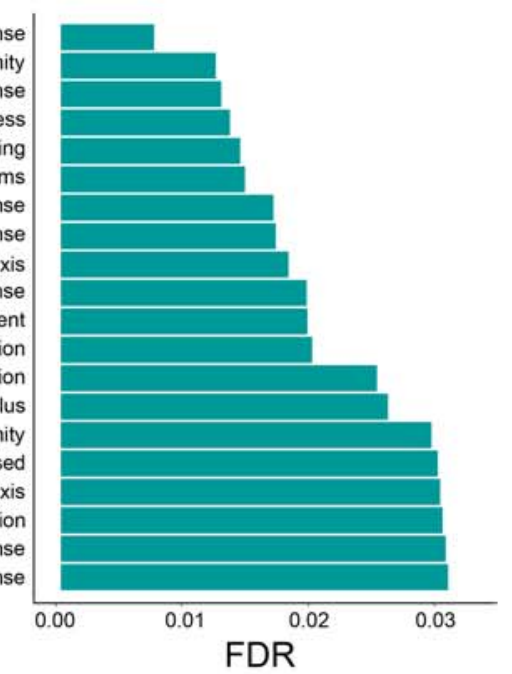

\section{Adaptive Immune Response}

\section{Innate Immune Response \\ Humoral immune response \\ Adaptive immune response based on somatic recombination of 1 immune receptors built from immunoglobulin superfamily domains Negative regulation of immune response O \\ Adaptive immune response ○ Immune Cell Activation Regulation of immune response Regulation of adaptive immune response Immune effector process} Positive regulation of immune response

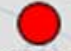

Multi-organism Process Innate immune response Regulation of multi-organism process Activation of innate immune response

0

0 Positive regulation of multi-organism process Response to biotic stimulus $\bigcirc$ Regulation of response to external stimulus $\bigcirc$ Positive regulation of response to biotic stimulus Positive regulation of response to external stimulus immune response Activation of immu Regulation of immune Positive regulation of immune system process

\section{Immune System}

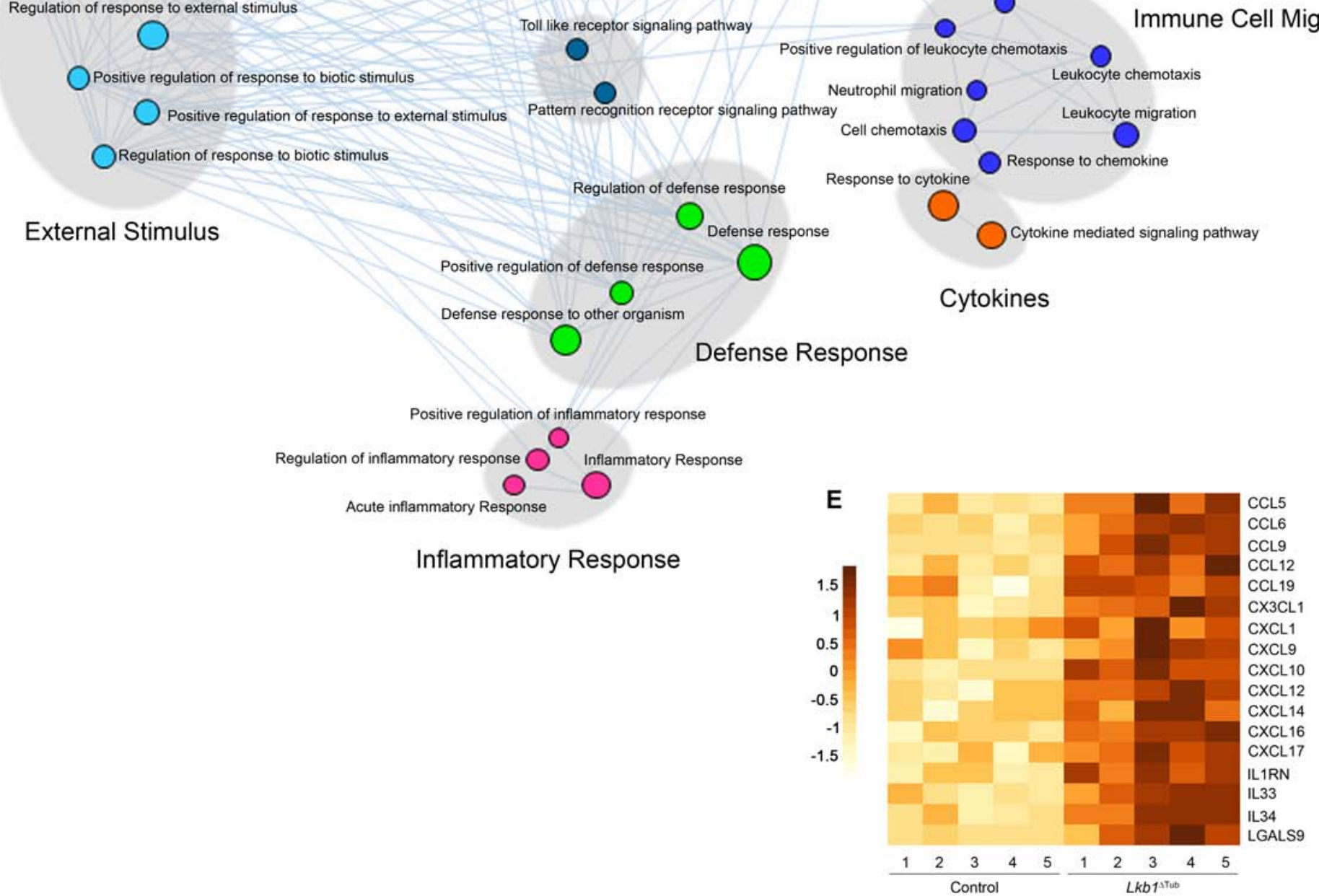


A

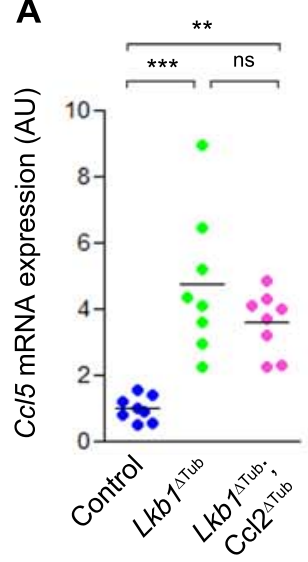

F

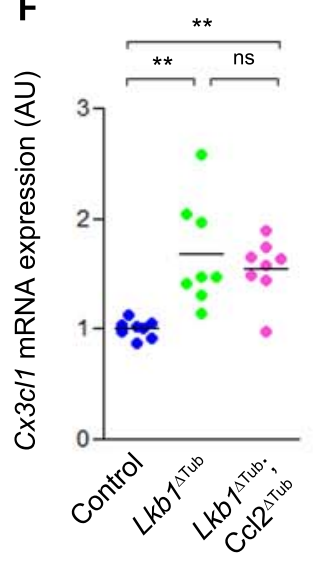

$\mathbf{K}$
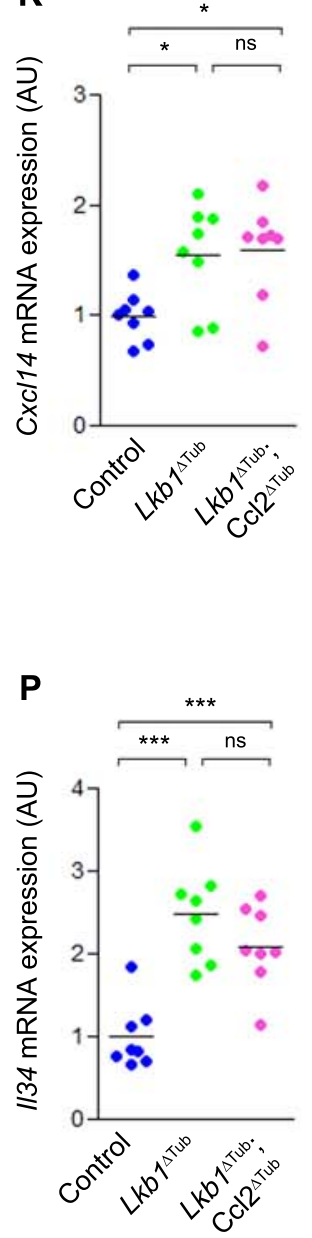

B

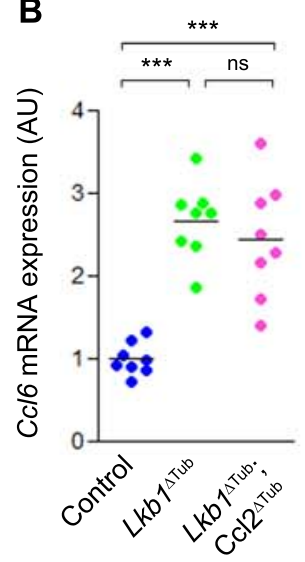

G
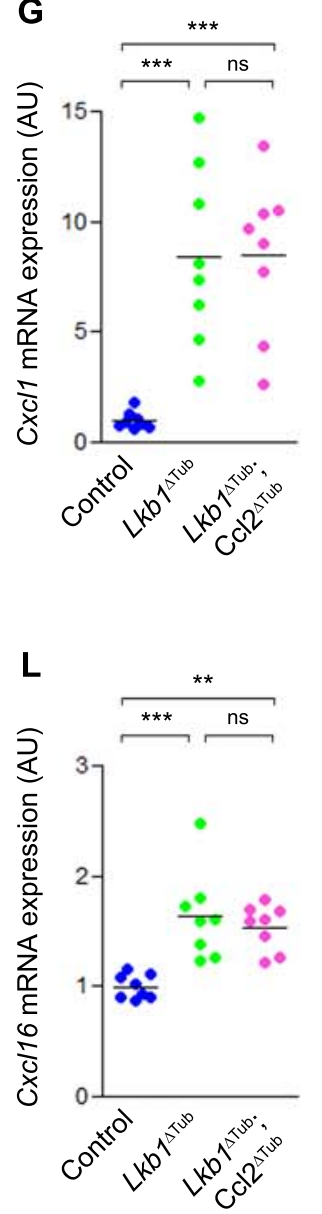

C

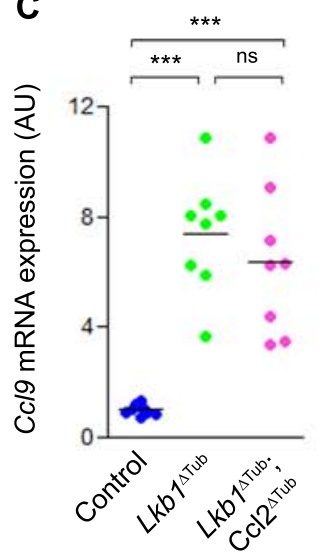

H
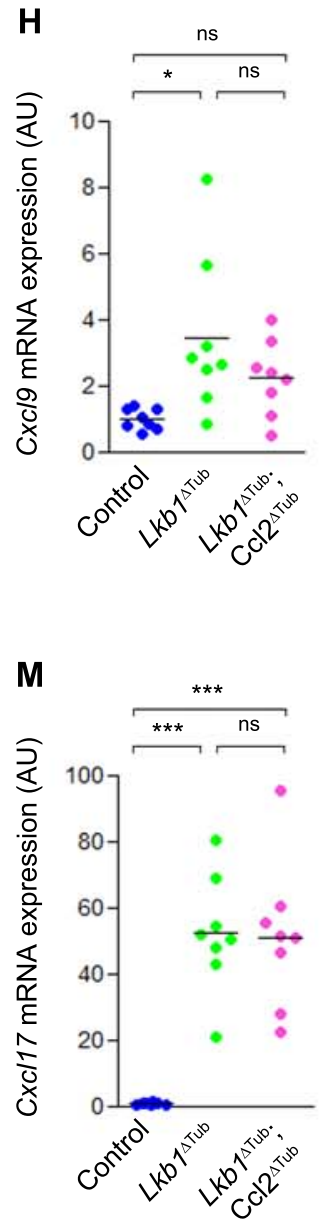

D
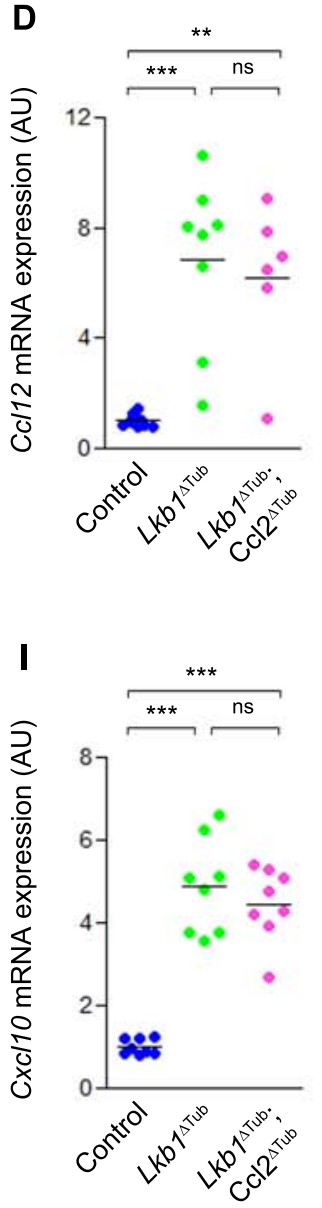

N

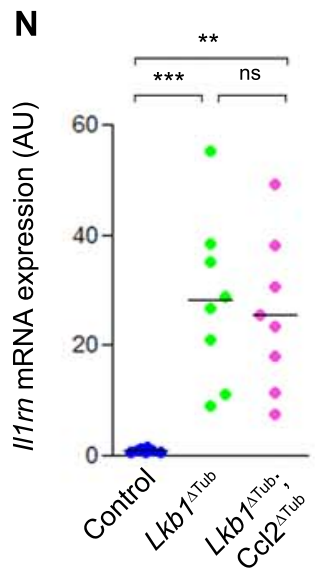

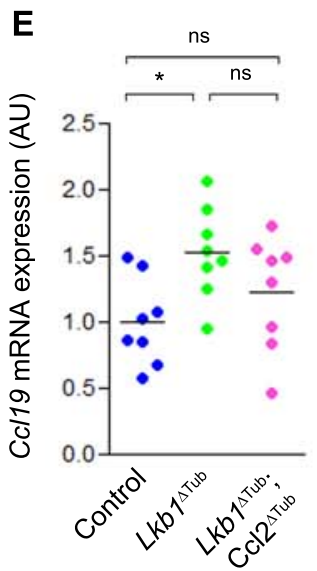

J

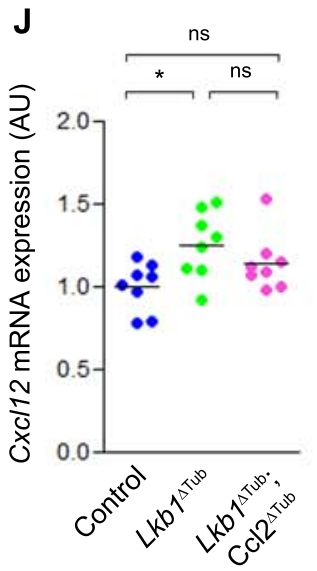

0

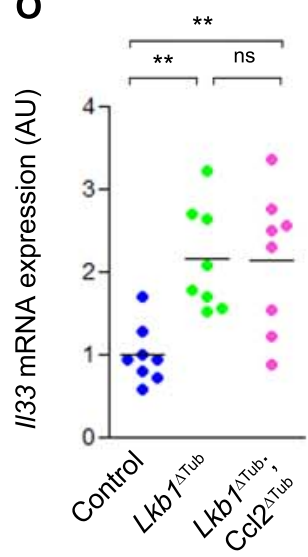

Q

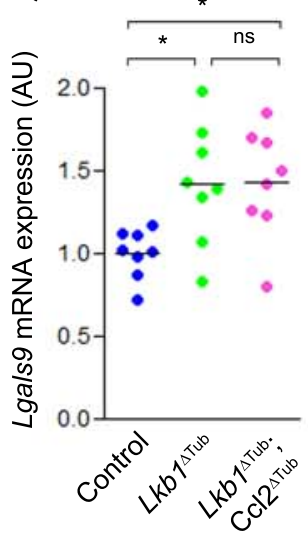


bioRxiv preprint doi: https://doi.org/10.1101/2021.01.07.425719; this version posted January 8, 2021. The copyright holder for this preprint (which was not certified by peer review) is the author/fuhdgunf pyhts reserved. No reuse allowed without permission.

A

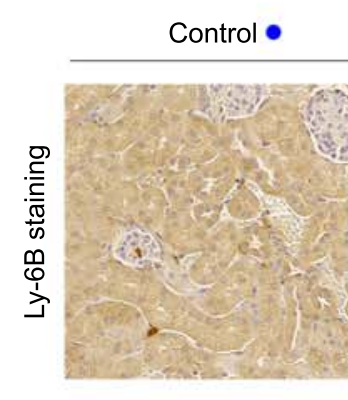

$L k b 1^{\Delta \text { Tub }}$

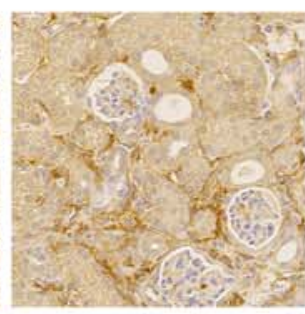

$L k b 1^{\Delta \mathrm{Tub}} ; C c / 2^{\Delta T u b}$

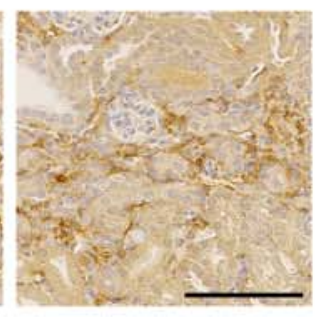

C

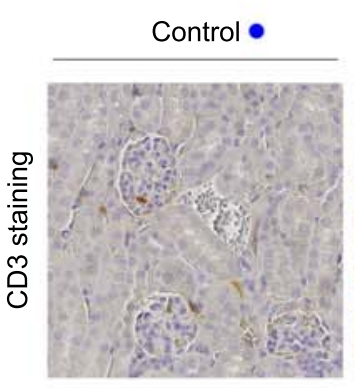

$L k b 1^{\Delta \text { Tub }} ; C c / 2^{\Delta \text { Tub }}$

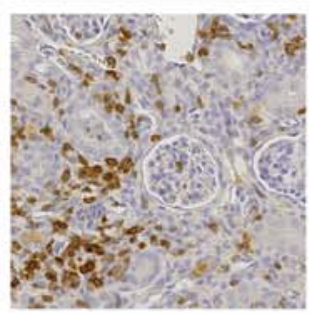

B

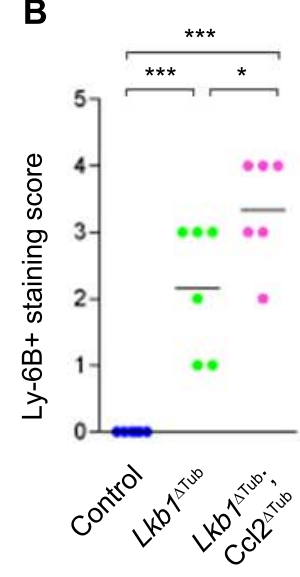

D

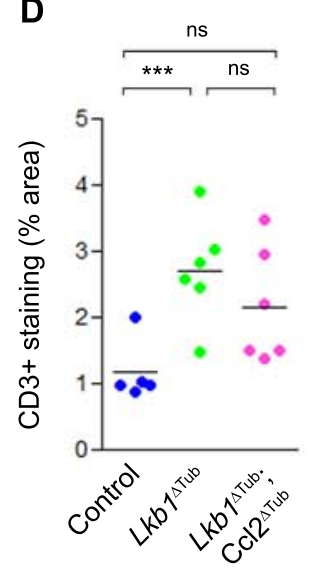

$\mathbf{E}$

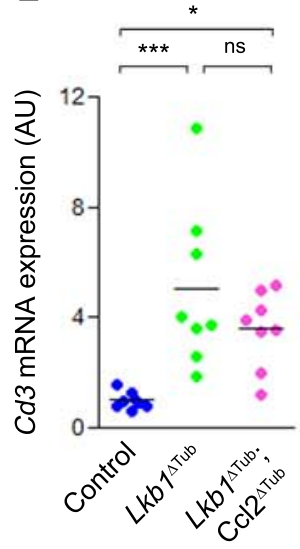


bioRxiv preprint doi: https://doi.org/10.1101/2021.01.07.425719; this version posted January 8, 2021. The copyright holder for this preprint (which was not certified by peer review) is the author/ffFidgurêl Gights reserved. No reuse allowed without permission.
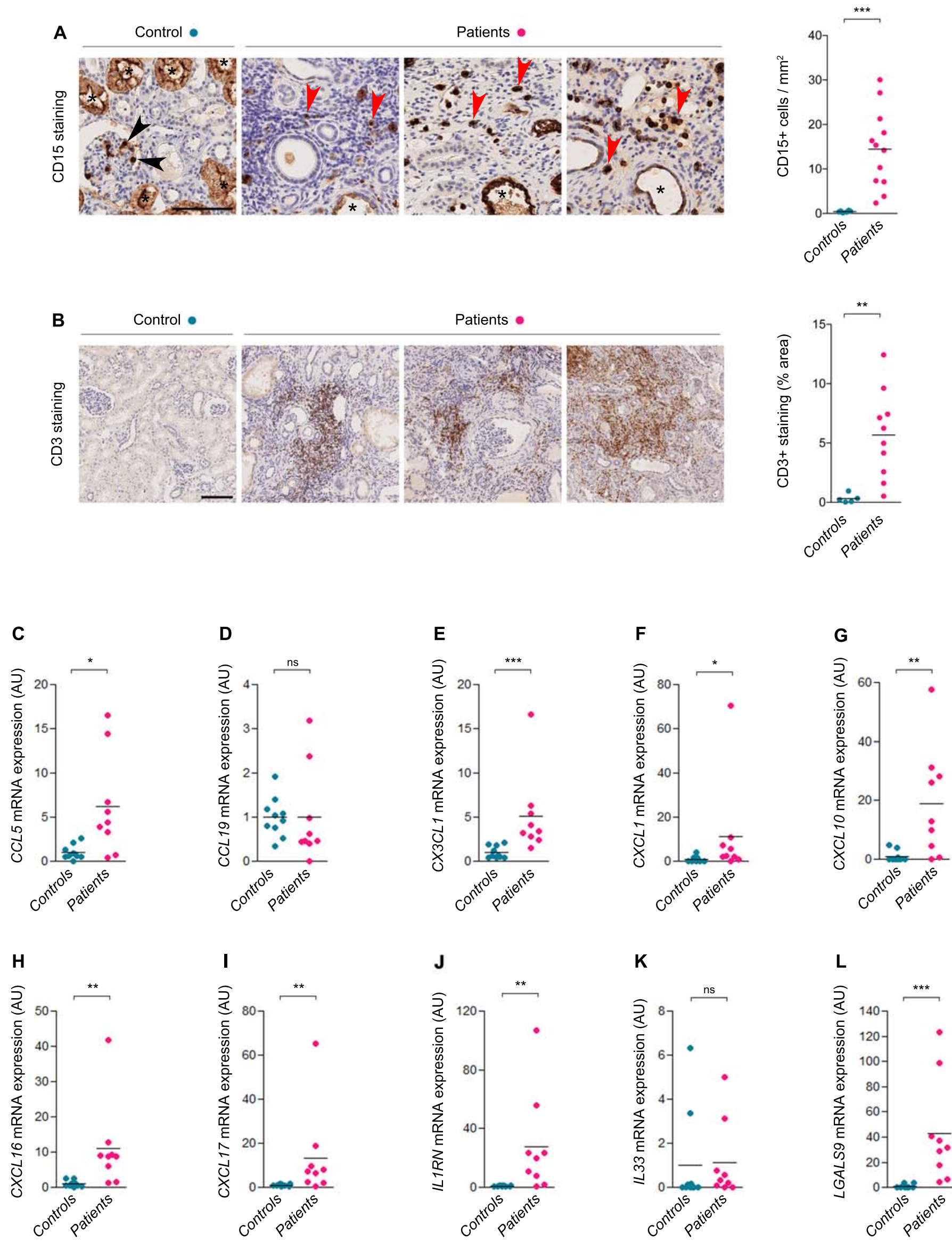

K

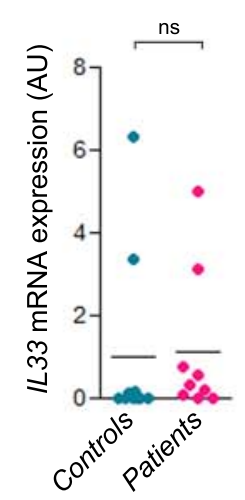

L

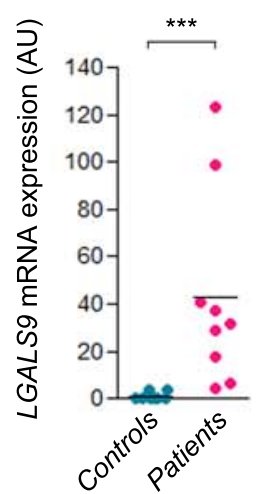

